\title{
Working from home and the explosion of enduring divides: income, employment and safety risks
}

\author{
A. Cetrulo ${ }^{2}$ D. Guarascio ${ }^{1,2} \cdot$ M. E. Virgillito ${ }^{2}(\mathbb{D}$
}

Received: 18 January 2021 / Accepted: 4 October 2021 / Published online: 18 January 2022

(c) Springer Nature Switzerland AG 2021

\begin{abstract}
Why are there so many non-teleworkable occupations? Is teleworking only a matter of ICT usage or does it also reflect the division of labour and the underlying hierarchical layers inside organizations? What does it happen to those workers not able to telework in terms of socio-economic risks, and how does the gender dimension interact with risk stratification? Hereby, we intend to shed light on these questions using a detailed integrated dataset at individual and occupational level (Indagine Campionaria delle Professioni, Indagine delle Forze di Lavoro and Inail archive) which provides information on different nature of risks (income, employment and safety). Our results entail that, first, class attributes, intended as execution of tasks, degrees of autonomy in doing the job, layers of the occupational categories, strongly influence the chance of working from home; second, those individuals who are not able to perform their work remotely are more exposed to transition to unemployment, to earn low wages, and to safety and health risks; third, being woman and employed with a temporary contract significantly amplify risk stratification.
\end{abstract}

\begin{abstract}
The authors wish to thank two anonymous reviewers for their helpful comments, participants to the ISS conference (July 2021), RDW conference 2021 (July 2021), SISEC conference (June 2021), ASTRIL conference (December 2020), GROWINPRO conference (December 2020), MINERVALAB seminar (October 2020). The authors acknowledge support from European Union's Horizon 2020 research and innovation program under grant agreement No. 822781 GROWINPRO Growth Welfare Innovation Productivity.
\end{abstract}

M. E. Virgillito

mariaenrica.virgillito@ santannapisa.it

A. Cetrulo

armanda.cetrulo@santannapisa.it

D. Guarascio

dario.guarascio@uniroma1.it

1 Department of Law and Economics, Sapienza University of Rome, Via del Castro Laurenziano 9, 00161 Rome, Italy

2 Institute of Economics and EMbeDS, Scuola Superiore Sant'Anna, Piazza Martiri della Libertà 33, 56127 Pisa, Italy 
Keywords Occupational structure $\cdot$ Teleworking $\cdot$ COVID-19 $\cdot$ Social divides

JEL Classification $\mathrm{J} 2 \cdot \mathrm{D} 2 \cdot \mathrm{D} 63 \cdot \mathrm{I} 14 \cdot \mathrm{C} 38$

\section{Introduction}

With the outburst of the COVID-19 induced crisis, societies are facing a major transformation of the established organization of productive activities, in particular the way in which work is physically performed at workplaces. Related, another deep challenge concerns the exploding socio-economic divides in the new pandemic phase. Indeed, not all segments of the population have been equally hit by the economic damages arising from the impossibility of performing their own job. For some segments direct and indirect pandemic risks have been stratifying and conflating. This is the case of Black, Coloured and Latino communities in the US which have been facing rising health and poverty risks (Selden and Berdahl 2020; Gonzalez et al. 2020; Montenovo et al. 2020). These workers however were suffering profound injustices in terms of access to medical assistance, income insecurity and occupational segregation well before the pandemic (Millett et al. 2020). Similarly, indigenous and suburb communities in Latin America did have far less chance to stay at home during lock-downs forced to choose between income security and health protection (Dueñas et al. 2020).

From the other side of the Atlantic, the Eurozone established for the first time a common plan to finance unemployment subsidies, the SURE, to face enormous job losses. However, European responses to tackle the labour market impacts of the COVID-19 crisis have been heterogeneous, ranging from extensions of sick-leaves, furlough schemes, redundancy pay systems, extraordinary income transfers, suspensions of layoffs. The only common denominator across all countries has been the switch to telework. Clearly, the higher the presence of social protection schemes and of labour market institutions operating in a given country, the lower the possibility that job losses will result into individual socio-economic risks. On the contrary, the higher the level of informality and the weakness of labour market institutions, the higher the associated individual risks.

In this paper we focus on a country presenting a combination of formal and informal labour markets, Italy, the first European economy hit by the pandemic and immediately adopting measures of social distancing since the mid of March 2020. As a consequence of lock-down measures, productive activities have been overwhelmed by the imposition of teleworking. Firms and public bodies have faced the pressure to reshape their organizational set-up introducing for the first time forms of remote-working. In Italy, however, working-from-home appears to be more a privilege for a few occupations rather than a generalized possibility. In fact, we recently documented that only thirty percent of Italian workers may work remotely (Cetrulo et al. 2020b). Those workers tend to belong to the upper echelon of the occupational distribution, are better remunerated and employed with permanent contracts. This figure has been confirmed by survey data reporting 
between 6.5 and 8 million workers abruptly shifted to remotely-work against approximately 500, 000 workers in 2018 (Fondazione Di Vittorio 2020). It is also in line with the US experience wherein, according to a web-survey carried out between April and June 2020 by Brynjolfsson et al. (2020), only one-third of the US workforce shifted to telework, confirming the previous estimate by Dingel and Neiman (2020). Other studies on advanced economies confirm this ratio, generally ranging from $30 \%$ to $50 \%$ of the workforce.

Why are there so many non-teleworkable occupations? Is teleworking only a matter of ICT usage or does it also reflect the division of labour and the underlying hierarchical layers inside organizations? What does it happen to those workers not able to telework in terms of socio-economic risks, and how does the gender dimension interact with risk stratification? Hereby, we intend to shed light on these questions using a detailed integrated dataset at individual and occupational level (Indagine Campionaria delle Professioni, Indagine delle Forze di Lavoro and Inail archive) which provides information on different nature of risks (income, employment and safety).

More in detail, to address the first question, after having distinguished among the two populations of working and not-working from home, we dissect which are the attributes of teleworkability. We resort to the anatomy of the Italian occupations developed in Cetrulo et al. (2020a) assigning scores to attributes of power, knowledge and learning, ICT skills, creativity and team-working, per each 4-digit occupation. Then, we investigate what happens to those segments not able to work remotely. In this respect, we study the events of transition to unemployment (occupational risk), of getting low-income (income risk) and of job related injuries and diseases (health risk). We therefore identify those occupations which face stratifying risks, namely characterized by the co-occurrence of these three events. We finally estimate a probit model at both individual and occupational level, accounting for a large set of covariates, and focusing on the role played by teleworkability, contractual, and gender as determinants of risk stratification.

The first result of our study is that class attributes, intended as execution of tasks, degrees of autonomy in doing the job, layers of the occupational categories, strongly affect the chance of working from home. Although the use of ICT devices and related knowledge are dramatically important to remotely-work, the degree of power and autonomy exercised in decision-making processes, and therefore the positioning along internal hierarchies, significantly differs between teleworkable and non teleworkable occupations. Women look to be endowed by a lower degree of power and autonomy compared to men in teleworkable occupations, and in general to be largely concentrated in the bottom part of the ISCO classification in non-teleworkable occupations, with gender and class divides intersecting. Moving to the stratification of socio-economic risks, according to our second result, those individuals who are not able to perform their work remotely are more exposed to the risks of becoming unemployed, earning a lower wage, and face significant safety and health risks. The most exposed occupations to risk stratification include food preparation-cooking-and-distribution personnel, waiters and similar professions, unqualified staff in charge of cleaning services in offices and shops, these latter being all professions with a predominant female 
share. Indeed, the third result entails that being woman and being employed with a temporary contract significantly amplify risk stratification.

The novelty of our contribution is threefold: first, we enrich the notion of risk stratification, bundling together three types of risk often thought to be unrelated to teleworking, and we detect the micro-occupational determinants of risk transition; second, we dissect the attributes of teleworkability and analyse the readiness of the Italian productive structure toward a potential durable teleworking shift; third, the use of micro-level information allows to exactly identify segments of the population toward which addressing selected policy interventions, beyond now-casting (AdamsPrassl et al. 2020b). Taken at large, our work supports the view that the COVID-19 crisis is more a syndemic rather than a pandemic (Horton 2020), characterised as it is by the interrelation between health and socio-economic risks. ${ }^{1}$ It is by no coincidence that what before was an unequal system of organizing societies it is now getting a socially unjust one (Dosi et al. 2020) marked by exploding enduring divides.

The paper is organised as follows: in Sect. 2 we discuss the streams of literature relevant to inform the empirical analysis, while in Sect. 3 we detail data, methodology and descriptive evidence. Results are shown in Sect. 4 and further discussed in Sect. 5 which concludes the paper.

\section{Background literature}

In this section we first discuss the evidence on diffusion and impact of teleworking as an organizational choice in usual times (Sect. 2.1), we next devote attention to teleworkability as a must in pandemic times (Sect. 2.2), and finally we highlight the relevance of the Italian case (Sect. 2.3).

\subsection{Teleworking as a choice in usual times}

The notion of "telecommuting" has been coined by Nilles (1975) with reference to the remotely execution of working tasks (including communications) at home or in other places different from the office. Early studies focusing on the diffusion of telework and related impacts on firms' and workers' performance have been stimulated by the outburst of computers (Nilles 1975) as well as by the effect of the 1970s' energy crisis on mass transport (Harkness 1977). However, contrary to the expectation of a progressive disappearance of offices and the spreading of nomad workers operating from their "electronic cottages" (Toffler and Alvin 1980; Makimoto and Manners 1997), telework has been only slowly diffusing, with the highest rates recorded in the Northern European countries, Japan and the US (Messenger 2017). Indeed, since 1980 the proportion of employees who primarily work from home has more than tripled and the range of teleworkable activities has also increased

\footnotetext{
1 The notion of syndemic proposed in Singer et al. (2017) highlights the interaction between the biological diffusion of human transmissible diseases (such as HIV) and socio-economic conditions.
} 
including a wide spectrum of service jobs, ranging from sales assistants and realtors to managers and software engineers (Bloom et al. 2015).

Sectoral, occupational and firm characteristics are crucial to understand the extent to which a given task is "teleworkable". Indeed, "teleworkability" depends on the executed functions, availability of computers and digital infrastructures allowing to perform tasks remotely, firm managerial and organizational capabilities, worker ICT skills (Bailey and Kurland 2002). In terms of hierarchical layers inside organizations (Huws 1991; Huws et al. 1999; Bailey and Kurland 2002; Corso et al. 2006; Neirotti et al. 2011), clerks, managers and professionals are seen as the most apt recipients of telework because of the more frequent use of computer, lower physical requirements and higher level of discretion and autonomy in defining the work pace characterizing those segments (Olson 1983). ${ }^{2}$ More recent evidence confirms the importance of adopting an occupational-based perspective to understand the patterns of telework diffusion, as the largest share of those working remotely are concentrated in specific occupational categories such as managers, professionals and, to a lower extent, clerical workers (Messenger 2019).

From micro-level occupational differences to country-level ones, telework diffusion ranges from $30 \%$ adoption rates in Sweden and Finland, to much lower rates recorded in Italy, namely $3.6 \%$ in $2018 .^{3}$ Those differences are mainly due to heterogeneity in ICT infrastructures and in active policies aimed at promoting the diffusion of ICT skills and internal workplace flexibility (i.e. flexible working hours) (Huws et al. 1999; Messenger 2019). Clearly, the industrial composition matters as well, with countries having larger shares of manufacturing less apt to teleworkability. Additionally, firm size matters being dimensionality a carrier of both technological and organizational capabilities. At the European level, Vazquez and Winkler (2017) report that the share of teleworking labourers has increased more than $15 \%$ in ICT intensive industries during the last decade, while according to the 2015 European Working Condition Survey (EWCS), around 13.5\% of European workers had some experience of telework, with only $5.2 \%$ of them usually working from home (Vargas-Llave et al. 2020). ${ }^{4}$

Teleworking is supposed to reduce spared time (log-in), eventual unproductive working phases (breaks) and sick leaves. This seems to be confirmed by Bloom et al. (2015) which find that being assigned to telework raises individual productivity. Dutcher (2012), via a quasi-experimental setting, shows that working from home can have positive implications on productivity in the case of creative tasks, while a negative relationship is detected in the case of repetitive and low-skilled tasks.

\footnotetext{
${ }^{2}$ Regarding managerial activities, Bailey and Kurland (1999) introduced the concept of "remote managing" referring to the possibility of controlling workers remotely and alternating face to face interactions with virtual management of subordinates.

3 Available here: https://ec.europa.eu/eurostat/web/products-eurostat-news/-/DDN-20200206-1.

4 The authors adopt an extended definition of telework including both working from home and other forms of ICT enabled remote working. About half does telework only occasionally while one-quarter performs remotely almost all tasks. Across the EU, the fraction ranges from $38 \%$ in the Northern-Eastern countries (Germany being the only exception at 13\%) to $16 \%$ in Spain and $7 \%$ in Italy.
} 
In terms of workers' satisfaction, Arntz et al. (2019), relying on the German Socio-economic Panel (GSP) between 1997 and 2014, highlight the importance of workers' socio-demographic characteristics: while childless employees, even working an unpaid extra-hour per week, report higher satisfaction due to telework, the latter penalizes women compared to men in terms of monthly wages, therefore increasing the gender-pay gap, with women accepting wage reduction against available free time to reconcile home caring schedules (Mas and Pallais 2017). Increasing overtime is also reported in Lott and Chung (2016).

Overall, if teleworking remains an attribute characterizing only few countries and occupations, having been generically configured as a complementary rather than a unique organizational choice, it is crucial to understand and detect which are the underlying characteristics making teleworking possible, and to estimate the socioeconomic risks for those who cannot telework. This is of paramount importance nowadays since teleworking has shifted from being an organizational option (based on workers' voluntary choice) for those few innovative firms and countries of adoption, to a must necessary to keep operating productive activities under pandemic times.

\subsection{Teleworking as a must in pandemic times}

Teleworkability significantly depends on technical attributes of occupations and on the internal division of labour and knowledge inside organizations. Jobs requiring in-person interactions, or alternatively, transforming external objects/environment and/or deploying complex and voluminous machines can hardly be performed from home. The opposite holds for jobs characterized by the use of ICT devices and software which do not require social exchanges. Therefore, the actual performed tasks, rather than the sheer sector of activity, represent the appropriate level of information to detect teleworkability. 5

Indeed, the explosion of the pandemic has seen the emergence of a growing literature based on occupation-level data to produce some quantitative assessment of the share of teleworkable jobs. The first study has been Dingel and Neiman (2020) which, relying on the US O*NET dataset, provides a figure of $37 \%$ of the US workforce having the technical feasibility to work from home. Occupations able to work from home include those in STEM, education, training, and library services, legal and financial activities and managerial ones. At the opposite are manual workers in building and grounds cleaning and maintenance, food preparation and serving, construction and extraction, and installation, maintenance, and repairing. Corroborating evidence is in Hensvik et al. (2020) which rely on the American Time Use Survey. Among the top-5 most teleworkable occupations at 4-digit, the authors report medical transcriptionists, computer scientists, economists, farmers and artists. Relying on the BIBB/BAuA Employment Survey for German jobs, Alipour et al. (2020) document that $56 \%$ of the workforce can potentially shift to telework. The estimate for

\footnotetext{
5 Occupation-level analyses are also extremely informative for what concerns individuals' location within the class structure of a society (Wright 1980, 1997).
} 
Italy stands at $30 \%$ according to Cetrulo et al. (2020b). Remarkably lower estimates are reported for Latin American Countries in Delaporte et al. (2021) and for overall developing countries in Gottlieb et al. (2021). Figures comparing European countries are reported in Palomino et al. (2020). All studies agree in documenting strong heterogeneity across sectors and occupations.

Granted such estimates, the question is what happens to the rest of non-teleworkable occupations. Confirming the evidence in Cetrulo et al. (2020b), Brussevich et al. (2020), covering 35 OECD countries, find that workers less likely to work remotely are largely concentrated in sectors more hit by the pandemic, such as accommodation and food services, transportation, and retail and wholesale sectors. According to their results, about $15 \%$ of the workforce employed is at high risk of layoffs mostly involving vulnerable occupations and sectors, and informal labour markets. Montenovo et al. (2020) report heterogeneous economic impacts of the pandemic across US subgroups. They identify the role played by occupational characteristics (degree of teleworkability and social interaction) and industry as pivotal in explaining job losses.

Systematic risk analyses are however scant. Beland et al. (2020), relying on the Current Population Survey (CPS) to study the impact of stay-at-home orders on employment and wages in the US, find higher job security for remote occupations. Consistently, Adams-Prassl et al. (2020a) report that the higher the fraction of tasks executable from home, the lower the risk for workers of being furloughed under the UK Job Retention Scheme. For Italy, Barbieri et al. (2021) and Boeri et al. (2020) have looked at those sectors of activity more exposed to contagion via physical proximity, with the highest exposure registered in the health sector.

In the following, we aim at contributing to the extant literature by focusing on the underlying characteristics of teleworkability, clarifying, first, which attributes of the working activities allow to telework and, second, quantifying, from a multi-level perspective, the socio-economic risks that those who cannot telework are facing.

\subsection{Reaction of the Italian labour market to telework}

Italy has been the first European country to implement social distancing policies. In the second half of March 2020, a decree of the Prime Minister imposed a lock-down to so-called "non-essential" activities, pushing both public and private companies toward telework. The local press welcomed such emergency measure as a chance to diffuse telework on a larger scale given that, in 2018 , only $3.6 \%$ of the Italian workers regularly worked from home according to Eurostat. ${ }^{6}$

Such an acceleration towards telework, however, has turned out to be uneven across sectors, occupations and workers, in turns unequally affecting an already divided labour market. Very often, not surprisingly, occupations that are non teleworkable are performed by low-income/precarious workers. As extensively documented (Cirillo et al. 2017, Cetrulo et al. 2021 for a review), during the last twenty

\footnotetext{
6 Available here: https://ec.europa.eu/eurostat/web/products-eurostat-news/-/DDN-20200206-1.
} 
years the Italian labour market became increasingly fragmented with a growing share of precarious jobs. The latter are concentrated in social consumption industry, i.e. tourism, restaurants, trade and retail, populated by SMEs with poor technological, organizational and financial capabilities, and largely located in the southern regions. Precarious jobs are indeed overrepresented in sectors most exposed to closures.

Despite the introduction of a Law forbidding dismissals for economic reasons, between March 2020 and April 2021 about 900,000 workers lost their jobs. Pandemic induced job losses are largely concentrated among young, part-time and temporary workers employed in the service sector with an annual contraction of $-2.8 \%$, $-3.7 \%$ and $-7.3 \%$ respectively. ${ }^{7}$ As expected, the major toll was paid by those who were structurally more fragile in terms of contractual regulations, sectors of activity and occupations. Among the latter, as early anticipated in Cetrulo et al. (2020b), there is a high incidence of workers performing tasks that cannot be accomplished remotely. This evidence asks for a more refined investigation of the ongoing risk stratification upon the most vulnerable segments induced by task-teleworkability.

\section{Data, methodology and descriptive evidence}

In this section we first present the integrated dataset used to conduct the empirical investigation (Sect. 3.1), and we then move to describe our classification to distinguish those occupations which can and cannot perform their activity from home (Sect. 3.2). Health risks deriving from working activity are presented in Sect. 3.3, while gender divides in terms of teleworkable occupations are discussed in Sect. 3.4.

\subsection{Integrated dataset description}

Our empirical analysis draws on the matching of three different databases, namely the RLFC-ISTAT (Rilevazioni Forza Lavoro) which allows to recover information on the Italian labour force at individual level, the Banca dati delle Professioni-INAIL which provides occupation-based information on working conditions, namely accidents at work and job-related diseases, and finally the ICP-INAPP (Indagine Campionaria delle Professioni) providing information on tasks and activities performed at workplaces. From the matching, we exploit a huge informative set, part of the so called Italian Informative System of Occupations (see Table 1 for more details). ${ }^{8}$

The RLFC collects detailed information on workers employment status, income, socio-demographic characteristics (i.e. education, age, gender, region), type of employment contract, 4-digit occupation, and sector of activity. The survey, an annually repeated cross-section, is conducted by the ISTAT three times per year with a quarterly frequency, interviewing around 250 thousand families resident in

\footnotetext{
${ }^{7}$ Available here: https://www.istat.it/it/files//2021/06/Mercato-del-lavoro-I-trim_2021.pdf.

${ }^{8}$ For other studies employing the RLFC-ICP matched dataset see Cirillo et al. (2021); Cassandro et al. (2021).
} 


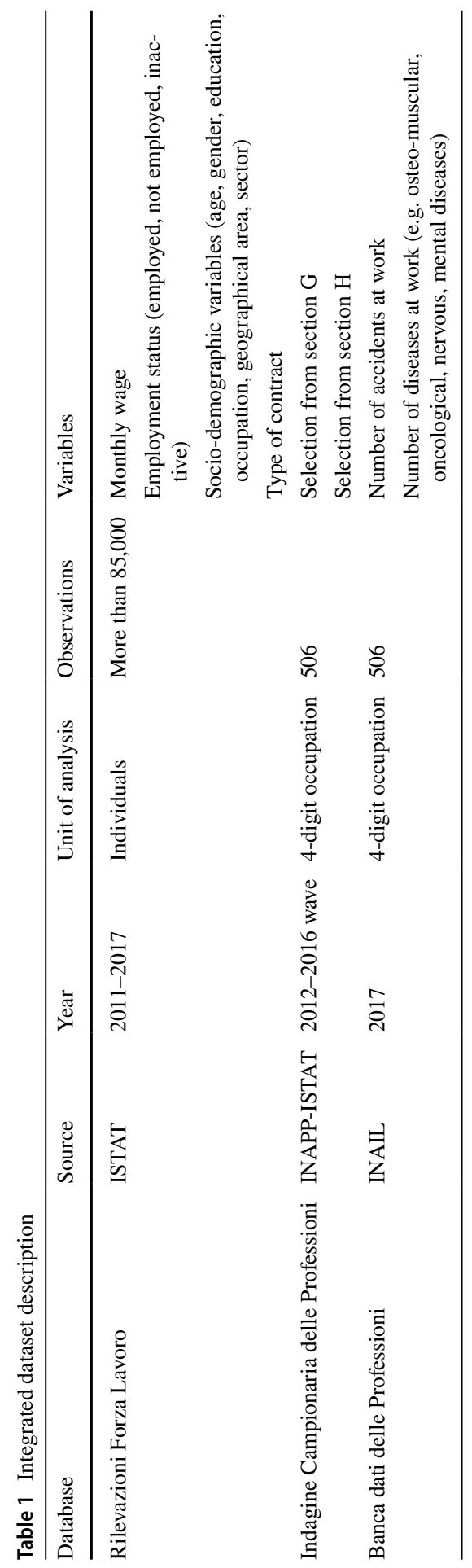


Italy, corresponding to a total of about 600 thousand individuals, across 1,400 Italian municipalities. Each individual is interviewed four times in two subsequent quarters, at year $t$, and in the corresponding quarters at year $t+1 .{ }^{9} \mathrm{We}$ focus on the most recent available wave, 2016-2017, while the remaining annual waves up to 2011 are used as robustness checks (available upon request).

The ICP represents the only European source comparable with the US O*NET, the latter being the most comprehensive database reporting qualitative and quantitative information on tasks, skills, work contexts and organisational characteristics at the 5-digit level of observation. The construction of the dataset entails a complex, multi-layer strategy of data collection and information processing allowing for both detailed occupational descriptions and inter-occupational comparability. Currently, two waves of the ICP database are available (2007 and 2012) with a spectrum covering 797 occupational codes, excluding armed forces. We rely on the 2012 wave. The interviews were administered to 16,000 Italian workers to ensure statistical representativeness with respect to sectoral, occupational, firm-size and geographical heterogeneity. Both $\mathrm{O} * \mathrm{NET}$ and ICP questions are organised in six main sections, expressions of a content model that simultaneously provides information from both a job-oriented and a worker-oriented perspective. The descriptors are: worker characteristics (enduring abilities), worker requirements (skills and education), occupational requirements (organisational and work context), experience requirements (training, cross functional skills), workforce characteristics (labour market information) and occupation-specific information (generalised activities and work context). Therefore, descriptors are formulated by making it possible to distinguish, for instance, inner individual abilities from competences acquired on the job. For each question, two rating scales are generally provided: level and importance. Questionnaire set-up, interviews administration and ex-post validation activities are designed to minimize subjective biases related to personal perspectives/attitudes.

The Banca dati delle Professioni released by the INAIL (National Institute for Occupational Accident Insurance) contains information on work accidents' and occupational diseases' incidence at 5-digit occupational level from 2017 to 2018. The public release of this dataset is part of an integrated project aimed at progressively matching different sources of information on occupations. To our knowledge, this is the first time the INAIL dataset is used in combination with other two sources of information on occupations. To get time-consistent estimation, we employ the cross-sectional 2017 wave.

\subsection{Working from home and teleworkability}

Our first step entails the identification of those occupations which can and cannot be performed from home (FH and NFH respectively thereafter). With this purpose, we start with the analysis of the ICP dataset. To identify those jobs, thirty questions

\footnotetext{
${ }^{9}$ For further information see https://www.istat.it/it/archivio/8263.
} 


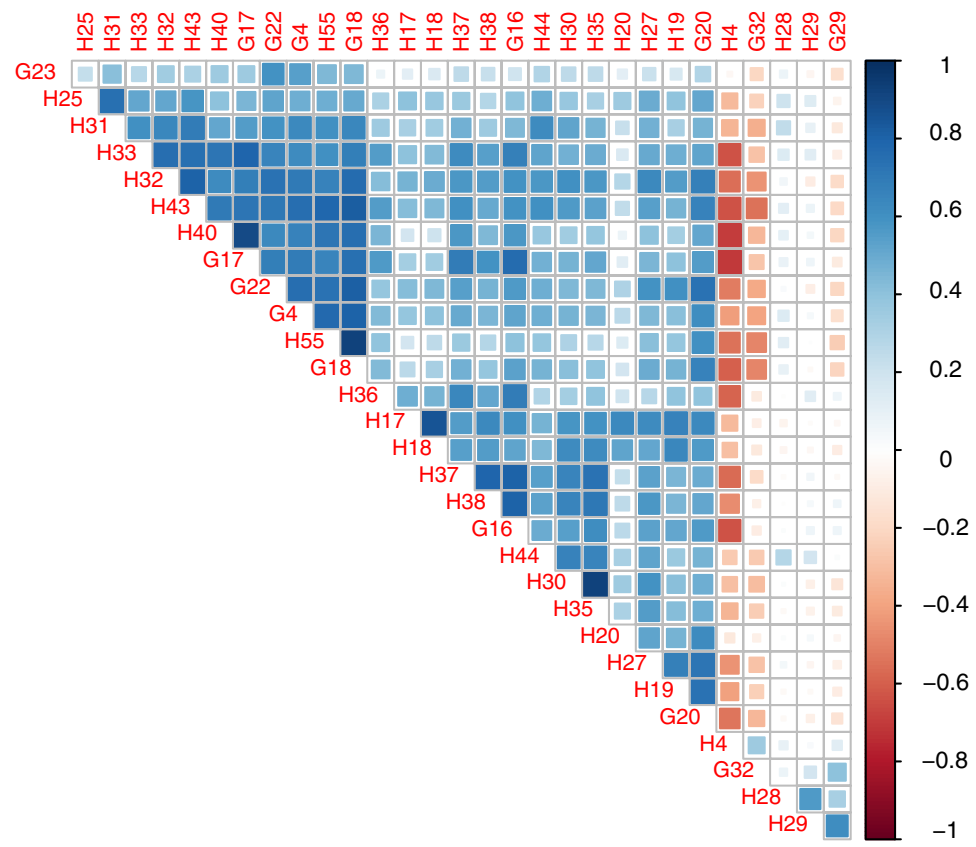

Fig. 1 Correlation matrix among ICP questions to construct the binary indicator

belonging to the "generalised activities" $(\mathrm{G})$ and "work context" $(\mathrm{H})$ sections of the ICP have been selected (see Table 6 in the Appendix for reference). ${ }^{10}$

Our analysis adapts and expands the methodology proposed by Dingel and Neiman (2020). The selected questions provide insights on the relative importance of:

1. performing activities involving (i) use, control and repairing of machines, equipment, vehicles, (ii) social contact, taking care of/or assisting others, (iii) email correspondence;

2. performing activities which (i) are carried out outdoors, (ii) require exposure to diseases and infections, (iii) imply the execution of risky movements or the wearing of protective equipment.

The correlation matrix in Fig. 1 shows a relatively low degree of overlapping information among our selected variables, and this supports our choice of retaining all thirty entries.

For each 5-digit occupation, ${ }^{11}$ these variables are ranked according to an importance or frequency scale ranging from 0 to 100 . In order for an occupation to be classified as "Not from home", most of the respondents should spend a large fraction

\footnotetext{
10 This section largely draws upon Cetrulo et al. (2020b).

11 The original unit of analysis in ICP is the 5-digit occupation. In order to link occupations data with National labour force survey, we aggregate information at the 4-digit level.
} 
of their working time in external environments or use equipment, machinery, tools. Alternatively, they should have continuous contact with the public.

More in detail, our indicator "Not from home" is a binary variable taking value 1 if at least one out of 29 questions (except the use of e-mail) shows a score equal or higher than 60 (corresponding respectively to "once or several times per week" in the time scale of section $\mathrm{H}$, and to "very important" in the importance scale of section $\mathrm{G}$ ), or if the question on the use of e-mail takes a value lower than 40; vice versa the indicator is equal to zero if for all 29 questions, intensities are lower than 60 , or alternatively if the question on the use of mail is higher or equal to 40 . The Appendix presents a series of robustness tests on the threshold level, variable selection and comparison with alternative available indicators.

Therefore, if for a given occupation most respondents report that it is very important to control machinery and use equipment, the latter cannot be carried out from home. Similarly, if most respondents report that they perform outdoor tasks for the majority of working time, this occupation cannot be carried out from home. Conversely, if sending e-mails represents a very infrequent activity, the occupation cannot be performed remotely. The classification is useful in order to identify jobs that can and cannot be executed from home on the basis of the actual performed tasks and work contexts, and starts by excluding all those occupations that require working in a well-defined physical space (e.g. because of the use of working instruments or because of intensive social contact). Of course, in case of compulsory social distancing, an occupation as primary school teacher which could not be carried out from home according to our classification, will eventually done remotely. In fact, there are tasks, largely related to activities as "taking care of others" or "working with the public" that could potentially be digitized, however at the cost of entirely reconfiguring the very nature of the profession.

An interesting example to appreciate and validate our classification is the case of teachers which, according to the education-level, belong to the two different categories. In fact, while school teachers cannot work from home, almost all university professors and researchers can actually perform their job remotely. This result depends precisely on the different degree of importance attributed by workers to social contact variables, being the latter more relevant in primary education. Overall, the index performs quite well in consistently assigning the entire set of 4-digit occupations $^{12}$ to the two groups From Home and Not From Home, in such a way that only eight occupations are manually moved from one group to another after an expost evaluation of the classification.

After identifying occupational categories at 4-digit, these are aggregated at 1-digit according to the ISCO classification, and then are linked to the Labour Force Survey providing information on the number of employees, wages, contractual types and socio-demographic characteristics of workers (age, gender and level of education). Table 2 presents the top-ten occupations at 3-digit for each category. Occupations are ranked in terms of the number of variable co-occurrences, out of thirty selected variables. The higher the number of co-occurrences, the higher the ranking.

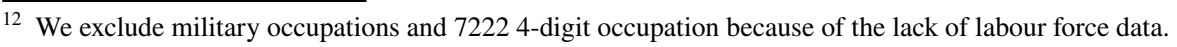


Table 2 Top-ten occupations which can and cannot be performed from home (3-digit, ISCO classification). Source: ICP-RCFL (2016)

Top-ten occupations which cannot be performed from home

644 Specialised forestry workers

711 Plant and machinery operators for the extraction and initial treatment of minerals

724 Machinery workers in plants for the mass production of wooden items

743 Agricultural machinery drivers

841 Unqualified mining and quarrying personnel

842 Unqualified construction personnel and similar professions

716 Plant operators for the production of thermal energy and steam, for waste recovery and for the treatment and distribution of water

645 Fishermen and hunters

712 Metal processing and hot working plant operators

612 Craftsmen and skilled workers in the construction and maintenance of building structures

Top-ten occupations which can be performed from home

252 Specialists in legal science

431 Employees in charge of the administrative management of logistics

254 Specialists in linguistic, literary and documentary disciplines

411 Secretarial and general affairs employees

121 Entrepreneurs and directors of large companies

122 Directors and general managers of companies

211 Specialists in mathematical, computer, chemical, physical and natural sciences

331 Technicians of the organization and administration of production activities

432 Economic, accounting and financial management employees

251 Management, commercial and banking science specialists

Occupations like woodcutters, miners, construction workers, fishermen rank among the top-professions which cannot be performed remotely. On the contrary, occupations involving specialised field knowledge, as legal or linguistic experts, managerial and executive professions are among the top ones which can be performed remotely. In terms of organizational hierarchies, occupations that cannot be performed remotely tend to be located at the low-end of the employment structure. On the contrary, those who self-organize their working activity, give orders or are responsible for high-level administrative tasks can operate remotely.

Overall, only $30 \%$ of the workforce has a job that can be done remotely, corresponding to broadly 6.7 million workers (2016 data). For the remaining part, including more than 15 million workers, the activities carried out and the work context to which they are exposed to do not make working from home feasible (Cetrulo et al. 2020b). This figure is in line with Dingel and Neiman (2020) reporting 37\% as the share of occupations which can be done from home for the United States. ${ }^{13}$ Notice

13 The authors extended the same analysis to 85 developed and developing countries, applying results from the US $\mathrm{O}^{*} \mathrm{NET}$ to national ILO data and finding a positive correlation between GDP per capita and the share of jobs doable from home. Indeed, this "once for all" approach disregards the importance of taking into account country level information on work content and executed activities for each occu- 


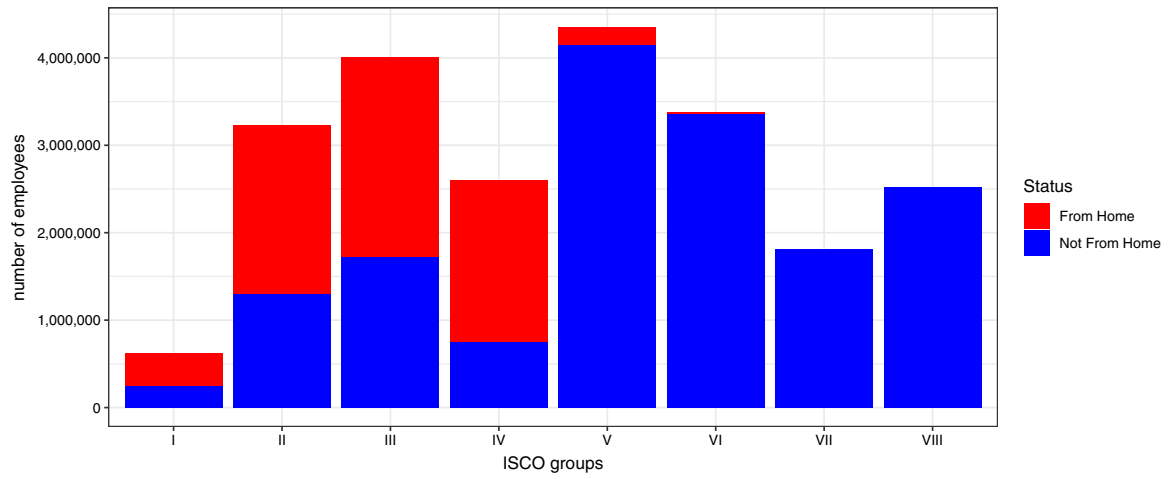

Fig. 2 Distribution at 1-digit (ISCO groups) for employees which can and cannot work from home. Source: ICP-RCFL (2016)

that our estimate becomes consistent with survey-based figures reporting between 6.5 and 8 million remotely workers in Spring 2020, once we account for school teachers.

By aggregating at 1-digit according to the ISCO classification and distinguishing for gender, in Fig. 2 a highly polarized occupational structure emerges with a strong concentration of opportunities to work from home for the upper four occupational groups. Working remotely is feasible for the majority of those who are at the top of the organizational hierarchy (managers, entrepreneurs and legislators), for scientificintellectual professions, for technical professionals. It increases in administrative tasks. For the lower part of the ISCO classification the scenario radically changes. Service-based occupations, such as entertainment operators, sales workers, artisans, plant and machine operators, as well as elementary professions, see the chance for working remotely drastically shrinking, or mostly nil. The first take home message from this battery of analyses is that working from home is more a privilege for a tiny fraction of the workforce rather than a generalized and widespread possibility.

Why teleworkability is so rare? We now turn to analyse which are the underlying determinants of working from home by employing for the two occupational categories the factor analysis developed in Cetrulo et al. (2020a), the latter developed to identify the dominant traits of the Italian occupational structure. According to their results the Italian occupational structure might be explained by five latent factors, with the factor collecting attributes of power, intended as the role in defining the division of labour inside organizations, explaining most of the variability. Other relevant factors are cognitive and manual dexterity, ICT knowledge, creativity, and team-work.

Footnote 13 (continued)

pational category. In our case, thanks to the ICP availability, we are able to do a consistent country level assignment both in terms of work content and labour force data. 


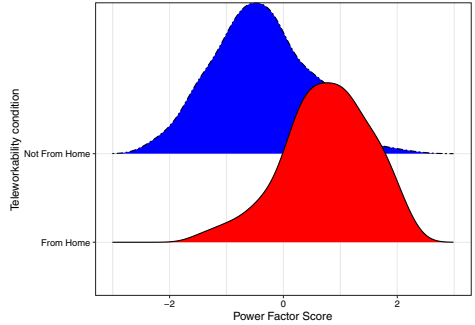

(a) Power

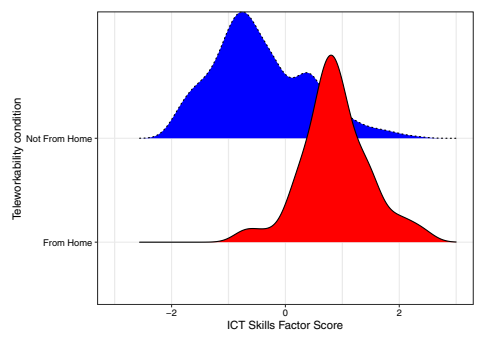

(c) ICT Skills

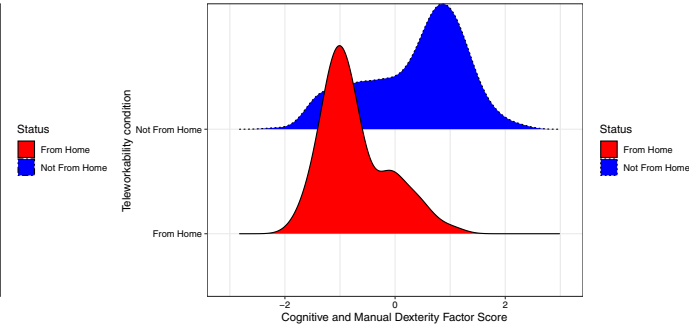

(b) Cognitive and Manual Dexterity

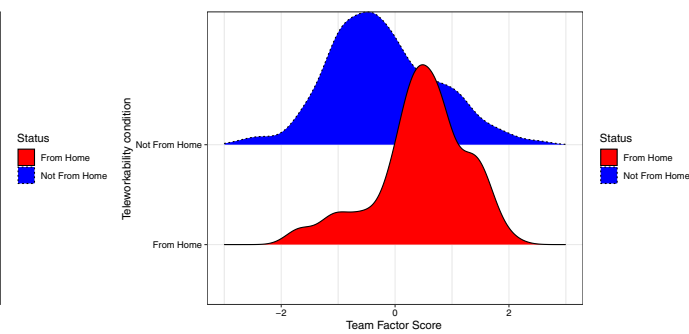

(d) Team

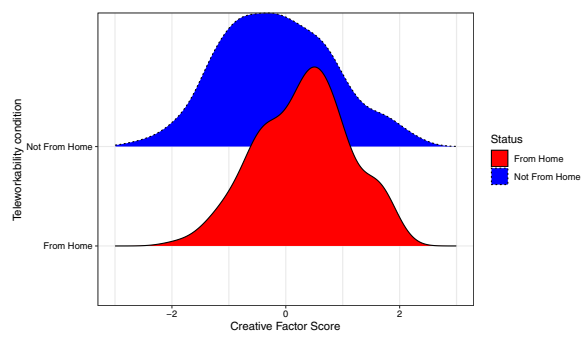

(e) Creativity

Fig. 3 Factor scores based on Cetrulo et al. (2020a) - Kernel density distributions for FH and NFH occupations

To which extent teleworkability is affected by these determinants? Fig. 3 shows the kernel density distributions at 4-digit level of the five factor scores applied to FH and NFH occupations. The factors read as (i) power, entailed by activities requiring decision-making authority, influence and control over other people, (ii) cognitive and manual dexterity, entailed by activities requiring both physical and cognitive selection of appropriate tools, inspection, control over the process, (iii) ICT knowledge, (iv) team, entailed by those activities requiring coordination with others, (v) creative, involving activities which require creative thinking.

Regarding the first three factors, the distinctive kernel density distributions highlight structural differences among the two categories. First of all, performing activities which entail the exercise of power attributes within organisations prevalently characterises FH occupations, confirming empirical studies underlying the importance of holding a relevant degree of autonomy, authority in doing the job, 


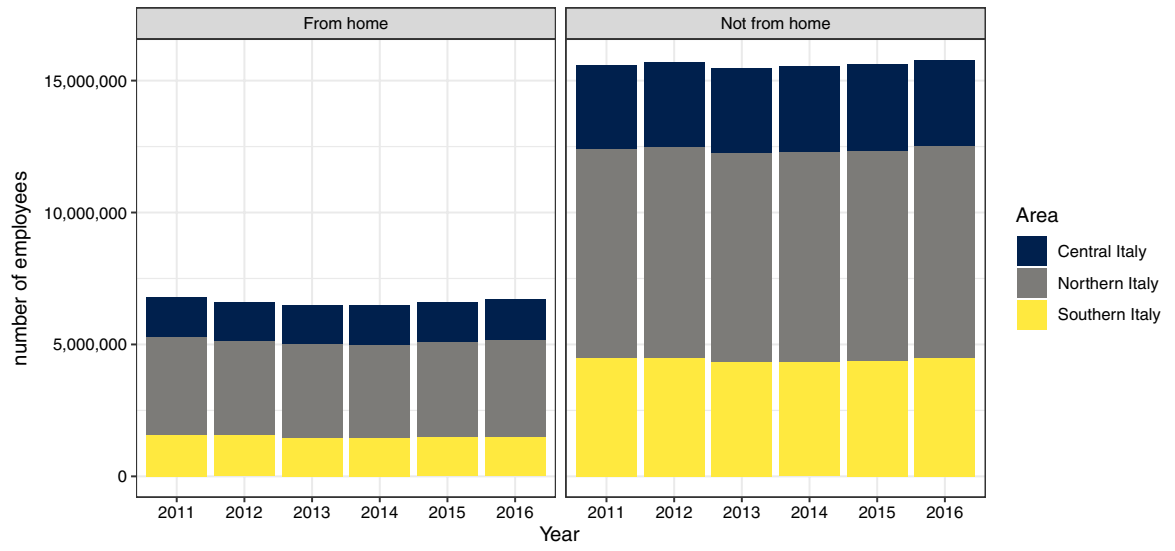

Fig. 4 Time-evolution in the number of employees by regional area and teleworkability (2011-2016)

and setting deadlines in order to be able of working remotely. ${ }^{14}$ On the other hand, those workers performing activities which require manual dexterity and cognitive ability in dealing with production processes, or in keeping the sequence of machine tools, are largely employed in non teleworkable occupations. ICT skills, which are notably under-diffused in Italy, mainly characterise FH jobs. A similar but less distinctive pattern is shown by team-working which in general prevails in FH occupations. Being creative is instead an attribute not such unique for neither categories. If teleworkability is not only a matter of executing (or non-executing) activities which require manual ability (Sostero et al. 2020), but it also regards the internal position inside organizations, say the hierarchical layer to which one belongs, it becomes even clearer why working from home is more a privilege for restricted social groups rather than a widespread opportunity.

We now turn to present some descriptive statistics on the employment evolution (2011-2016) of occupations distinguished in the two categories (FH and NFH respectively). Indeed, if teleworking from being an organizational option becomes a compulsory choice, it is important to understand the degree of readiness of the Italian occupational structure in absorbing/generating those teleworkable occupations. During the period under analysis no relevant discontinuity in the growth rate of the two groups can be observed (Fig. 4), with a stable figure of less than 7 million workers employed in teleworkable jobs with respect to about 15 millions in non-teleworkable jobs. Together with a stable trend in NFH occupations, regional disparities clearly emerge, being those relatively few teleworkable occupations concentrated in the North.

\footnotetext{
14 Despite relatively similar "technical feasibility", diffusion of telework practices has been significantly different between managers and keyboard clerks (Milasi et al. 2020).
} 


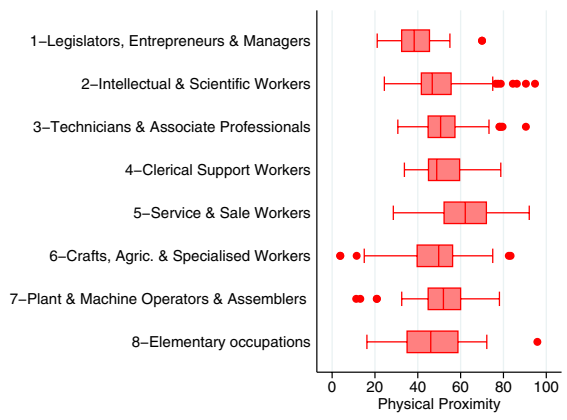

(a) Physical proximity

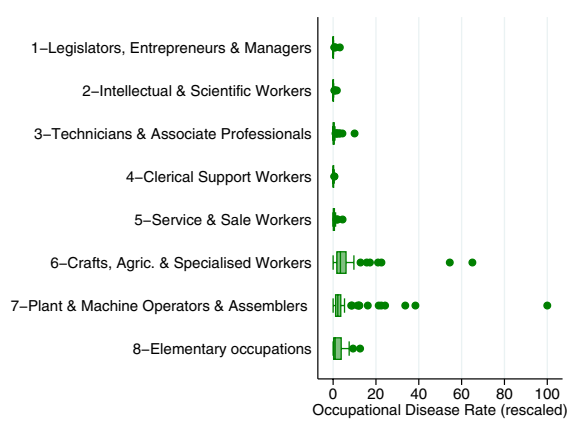

(c) Occupational disease rate

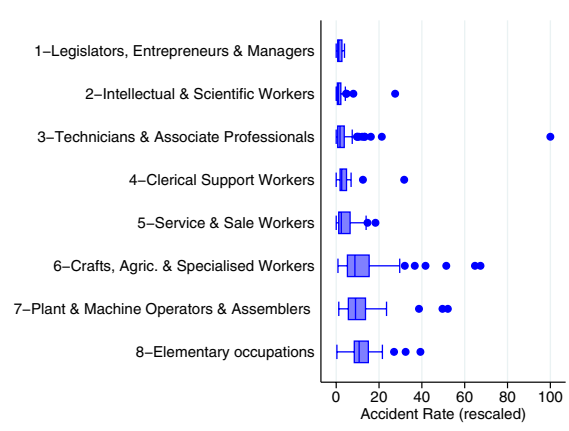

(b) Accident rate at work

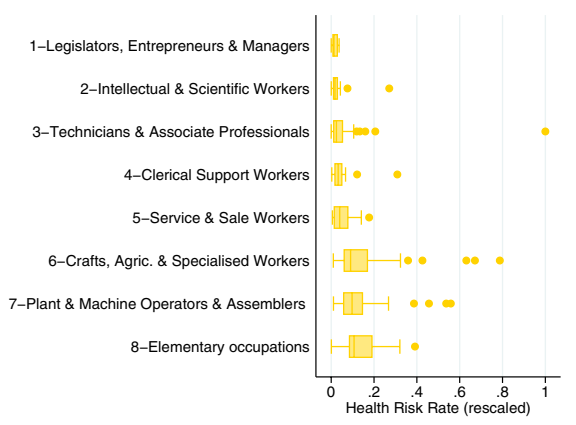

(d) Health risk

Fig. 5 Distribution of physical proximity (ICP), accident rate at work (INAIL), occupational disease rate (INAIL), health risk (authors' elaboration combining accident and disease rates) at 1-digit (ISCO classification)

\subsection{Health risk at work: physical proximity, accident rates and occupational illness}

If working from home represents a privilege in terms of employment stability and income security, with the outburst of the pandemic FH occupations appear also to be the most resilient to the risk of contagion. Indeed, face-to-face interactions represent one of the thirty variables included to characterize the two populations: who can telework enjoys also the chance of reducing interpersonal contacts.

Physical proximity and face-to-face interactions have been used to identify sectors of activity and related occupations more exposed to contagion risk (Barbieri et al. 2021), retrieving information from the corresponding ICP variables. We deem this approach too restrictive to estimate the risk of contagion: physical proximity might be the result of the very nature of the working activity (primarily in the health sector), but also of the physical organization of workplaces (take the case of assembly workers using common spaces as canteens or wardrobes, or of open-space offices in administrative services). The use of the ICP variable tends to confine contagion risk to a sector-specific event, leading to a potential 
underestimation of the risk level in non-health and non-service sectors. For example, in manufacturing or in elementary occupations, workers tend to under-report face-to-face interactions and physical proximity. However many activities are actually performed in quite crowded workplaces, while sharing of workstations with other operators often occurs. Our doubt is confirmed by the distribution of physical proximity across 1-digit occupational groups: it is a prevalent variable, above $60 \%$, only for service and sales workers while it disregards the majority of other occupations (Fig. 5.a).

Relying exactly on disease exposure, physical proximity and gathering, the first release of the INAIL classification on sectoral contagion risks, adopted to regulate workplaces during the post lock-down phase, ranked doctors, nurses, pharmacists, police agents, funeral parlours and hairdressers as the most exposed workers, while a low degree of contagion risk was assigned to manufacturing and logistics workers (INAIL 2020a). However, update figures on contagion at workplaces showed an increasing number of cases in logistics and meat processing plants (INAIL 2020b), wherein working and employment conditions are far from being safe even in normal times (EFFAT 2020). Although at the beginning of the pandemic the highest recorded cases were in hospitals, mainly because of the lack of protective devices and adequate sanitizing procedures, recent data record a significant increase in contagion rate within sectors of activity initially classified at low risk.

To overcome these limitations, we construct a more comprehensive indicator of the actual conditions of safety and health at workplaces, looking at cases of accidents and occupational illnesses collected by the INAIL database. In fact, even if not directly informing about contagion risk, structural, pre-existing information on health and safety conditions at work might be a proxy for the status of existing (or not) employee protection schemes, at each 4-digit occupational level. Figure 5.b and c show the distributions of these events across 1-digit occupations. Although rare, because only certified by legal procedures, accidents and diseases are more concentrated in the bottom part of the ISCO classification.

Looking at the joint distribution of occupational illnesses and accident rates (defined as health risk in Fig. 5d) offers a comprehensive understanding on safety conditions at work, considering a variety of physical and psychological risk factors. Not surprisingly, the explosion of the pandemic has also spurred inequalities in terms of health at work. These disparities do not only depend on the type of job performed, but they are strictly related to both socio-demographic and organisational factors (ETUI 2020). Adopting or not rigid health and safety protocols within firms becomes crucial to prevent contagion. ${ }^{15}$

\footnotetext{
15 For example, during the second wave of contagion in France, 29\% of new detected clusters between May and September 2020 occurred in non-healthcare workplaces. According to ETUI, this is due to scarce workplace prevention and absence of improvements in terms of work-organisation: see https:// www.etui.org/news/france-work-key-covid-19-contaminator.
} 


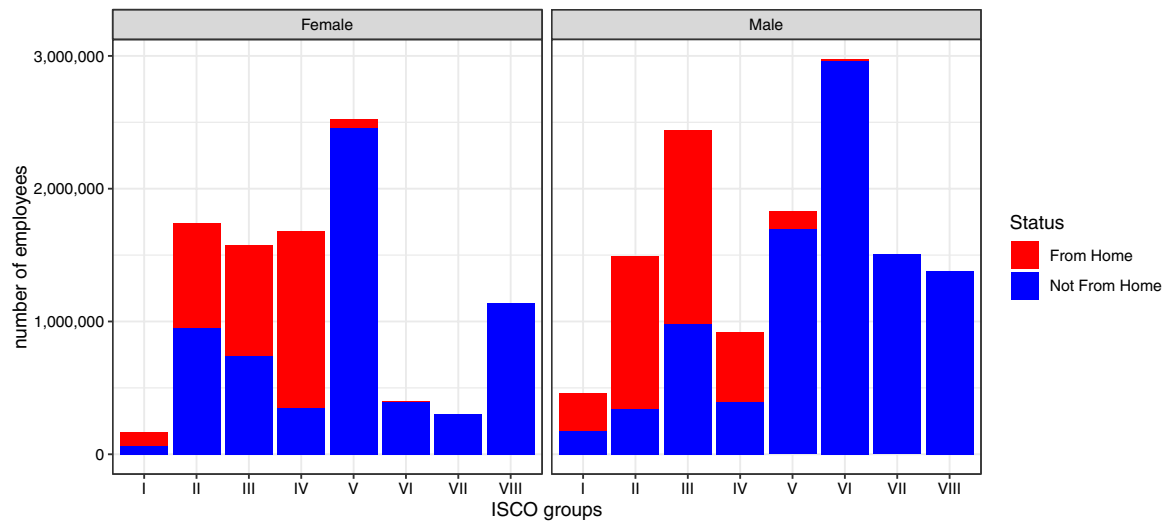

Fig. 6 Gender distribution at 1-digit (ISCO classification) for employees which can and cannot work from home

\subsection{Gender divides}

Up to the COVID-19 crisis, male and female occupations have never been such differently hit during downturns: recent empirical evidence documents the phenomenon of she-cession to underline the asymmetric labour market effects suffered by women, either for occupational segregation in sectors more exposed to closures (e.g. social consumption services), or for the highly unbalanced distribution of domestic burden, inducing many women to leave their job to taking care of children (Zamarro and Prados 2021; Farré et al. 2020).

Risks, vulnerabilities and socio-economic hardships affecting women intersect in the pandemic phase. With reference to Italy, on the one hand, many women kept working because employed in so-called essential sectors but, on the other hand, those who carried out domestic and care jobs, such as housekeepers and carers, were largely unable to access income and welfare supports due to the still predominantly irregular and informal nature of employment relationships in this sector. In terms of load of housework and work-life balance, mothers of children in the $0-5$ age enormously suffered the burden of the lock-down (Del Boca et al. 2020).

A gender dimension enlarges our comprehension of risk stratification. Figure 6 presents the breakdown of FH and NFH occupations by distinguishing between male and female workers. Women working from home are mostly concentrated among clerical support workers doing administrative activities and to a less extent among scientific and technical professions. They hardly materialize among the top professions of the first ISCO group. Teleworking women, although maintaining income and job, enormously suffered the burden of conciliation between working and caring activities, primarily children education. Non-teleworking women, which indeed represent the largest fraction, are mainly concentrated among service and sales, and elementary occupations: together with the care-work burden, they had also to cope with income, employment and safety risks. 


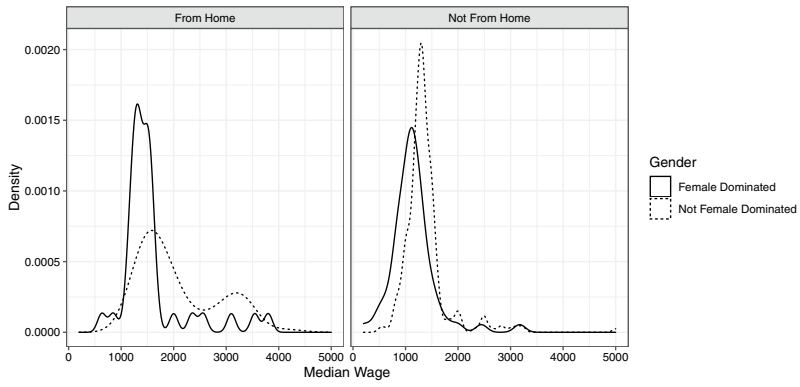

(a) Wage distribution by gender for $\mathrm{FH}$ and $\mathrm{NFH}$ occupations

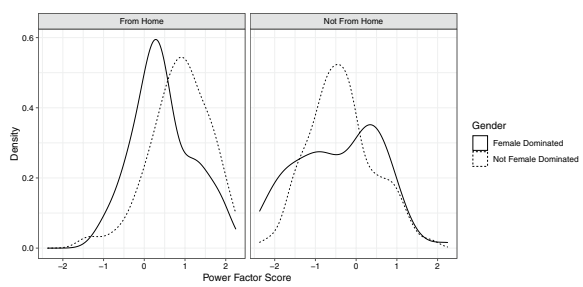

(b) Power factor score by gender for FH and NFH occupations

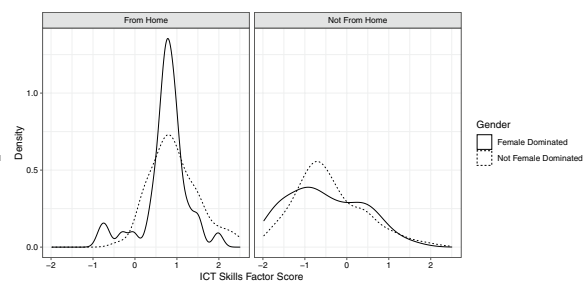

(c) ICT skills factor score by gender for $\mathrm{FH}$ and $\mathrm{NFH}$ occupations

Fig. 7 Kernel density distributions of wages, power and ICT skills factor scores by gender and status

Patterns of occupational segregation, detailed at 3-digit level in Table 7 in the Appendix, map into lower income (Fig. 7a) and lower power in female dominated professions (Fig. 7b), which also look to be endowed by lower ICT skills (Fig. 7c). Indeed, power and ICT skills predominantly characterize teleworkable jobs and therefore appreciable heterogeneities regard $\mathrm{FH}$ occupations, in accordance with Fig. 3.

\section{Estimates of risk stratification}

After having identified (i) occupations which can and cannot be performed from home, (ii) the underlying attributes of teleworkability, (iii) the importance of considering a more comprehensive nature of safety conditions at work, (iv) gender divides in the access to teleworkable occupations, we now move toward the empirical estimation of three forms of risk, namely employment, income and health safety. The goal is to verify whether a different risk profile emerges with respect to the probability of losing the job, earning a low income and facing more frequently accidents at work and occupational illnesses, which will be our outcome variables, once we classify workers according to their teleworkability, also in line with the extant literature (Mongey and Weinberg 2020).

Figure 8 shows the histograms of our three outcome variables distinguishing between FH and NFH occupations. Already at a first glance it emerges a distinctive pattern characterizing the two populations: indeed all three events are extremely 


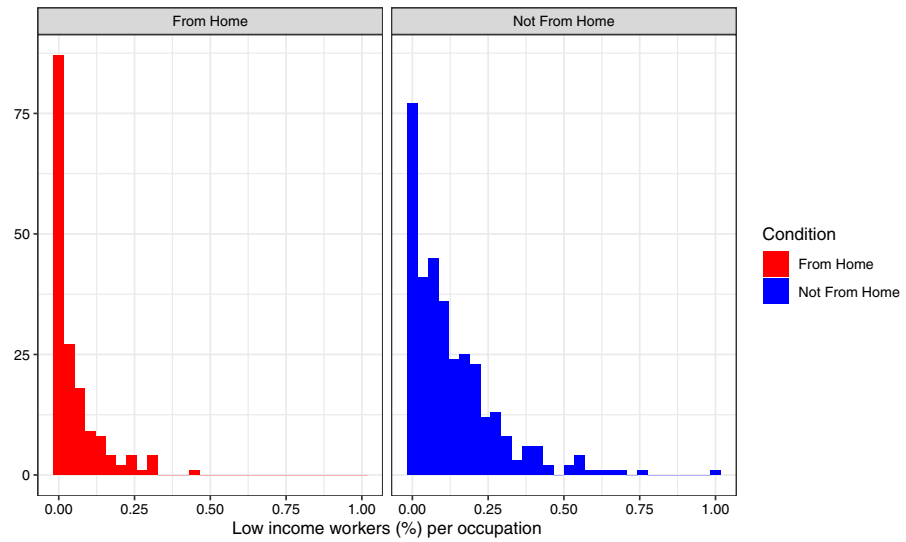

(a) Low income distribution

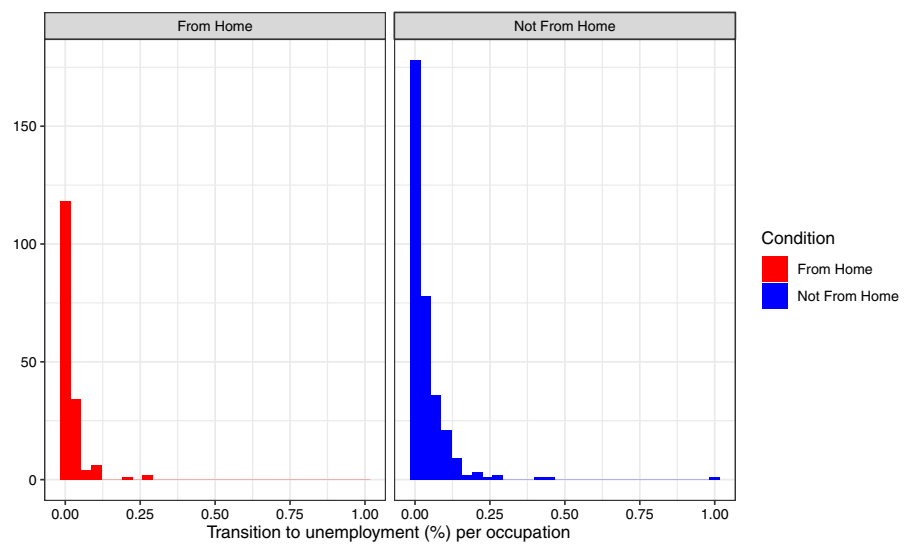

(b) Transition to unemployment distribution

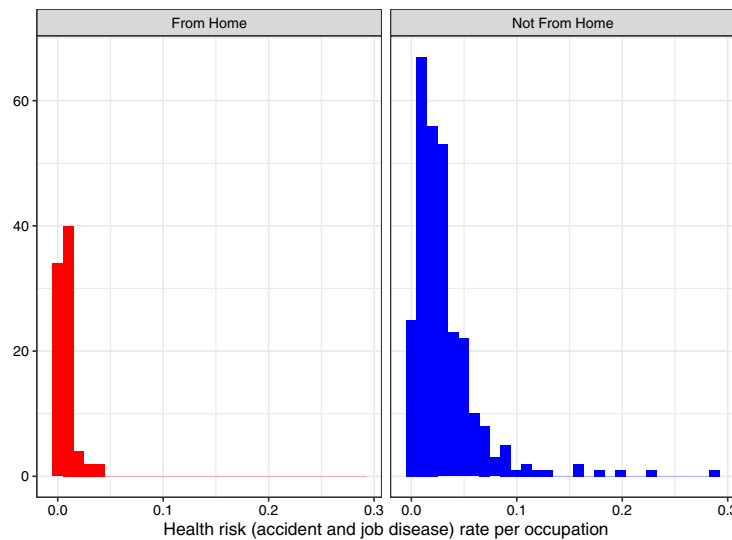

Condition

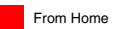

Not From Home

(c) Occupational disease and/or accident at work rates distribution

Fig. 8 Histograms of the events: a earning a low income; $\mathbf{b}$ transition to unemployment; $\mathbf{c}$ having an accident at work and/or occupational illness 
concentrated among not working from home occupations, while the frequency of occurrence strongly decays for the other group.

Tables 8, 9, 10, 11 in the Appendix present the co-occurrence of the three events for occupations at 4-digit, considering all possible combinations. They are indeed quite revealing, pointing at occupations such as "Retail sales assistants", "Industrial product packaging machine workers", "Unqualified cleaning staff in accommodation services and ships" among the most exposed to multi-dimensional risks (Table 8). If we exclude health risk (Table 9), female dominated professions such us "Supervisors of children and similar professions", "Personal care workers", "Machinery operators for the treatment and conservation of food" come more prevalently, while occupations in essential and caring activities as "Workers in charge of hygiene and cleaning services" and "Qualified professions in health and social services" emerge when looking at the co-occurrence of low-income and health risks (Table 10). Finally, manual workers and machine operators are more exposed to combined employment and health risks (Table 11). We are therefore able to pinpoint stratifying vulnerabilities.

\subsection{Empirical strategy and variables description}

The estimation strategy applies the binary response methodology on two different databases:

- a micro dataset built merging ISTAT RLFC-ICP, on which we estimate for each individual $i$ those factors affecting the probability of (i) transition to unemployment, and (ii) earning a low income;

- an aggregated data-set merging ICP-INAIL-ISTAT, where for each occupation $j$ at 4-digit we look at those characteristics having an impact on the probability of (iii) low income, and (iv) high accident risk and illness at work.

We assume that the response probability takes the following form: ${ }^{16}$

$$
\begin{aligned}
P(y & =1 \mid \mathbf{x})=P\left(y=1 \mid x_{1}, x_{2}, \ldots . x_{k}\right)=G(Z) \\
G(z) & =\Phi(Z)=\phi(v) d v
\end{aligned}
$$

with $\phi(z)$ being a standard normal density function:

$$
\phi(z)=(2 \pi)^{-1 / 2} \exp \left(-z^{2} / 2\right)
$$

We perform four univariate probit models, with dependent variables expressed as binary dummies:

$\overline{16}$ See Wooldridge (2006) for further details. 


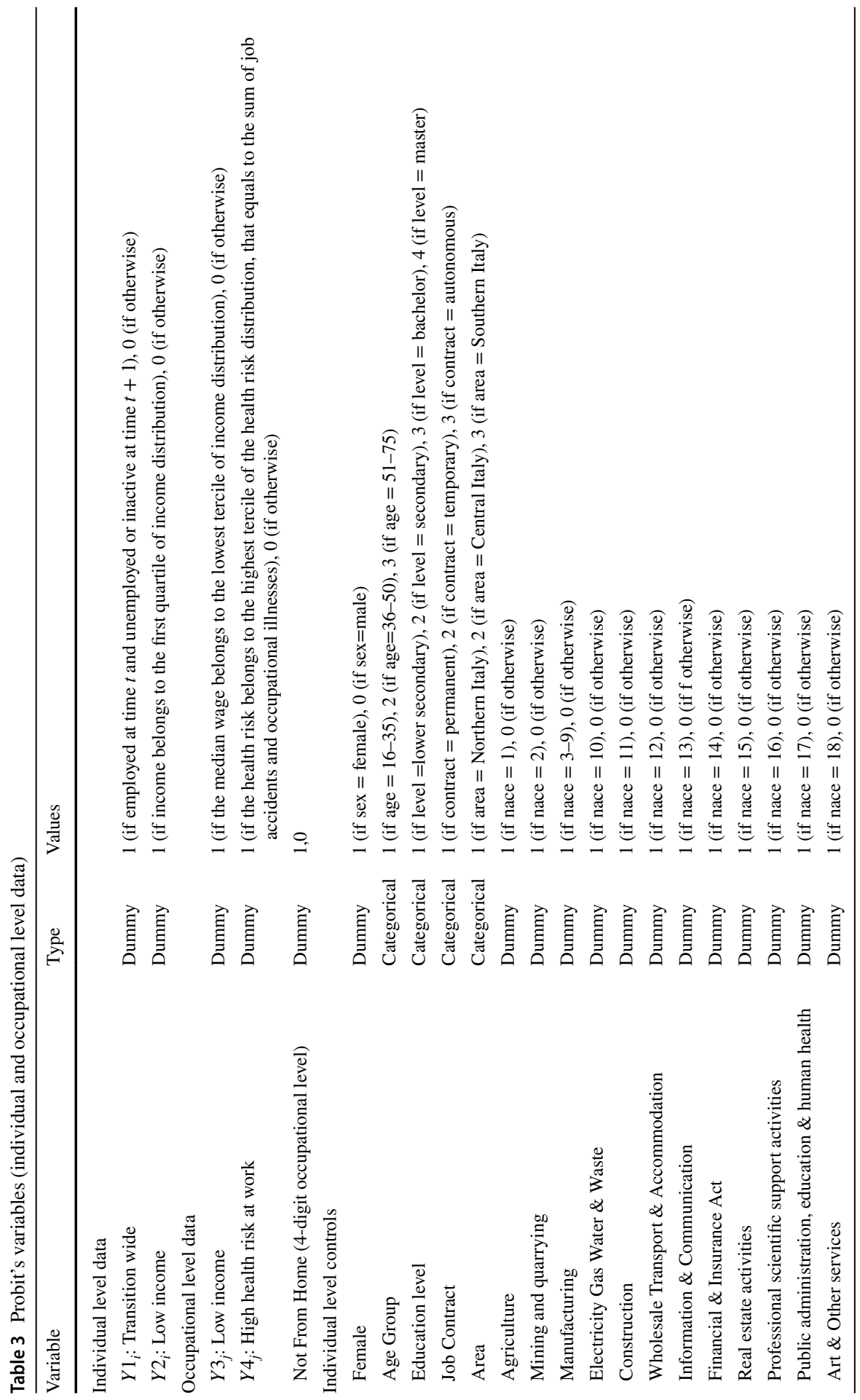


1. Transition to unemployment $(i): Y 1_{i}=0,1$, where $Y 1_{i}=1$ if individual $i$ is employed at time $t$ but he/she becomes unemployed or inactive at time $t+1$; $Y 1_{i}=0$ if otherwise;

2. Low income $(i): Y 2_{i}=0,1$, where $Y 2_{i}=1$ if the income of individual $i$ belongs to the lowest income quartile of the entire workforce wage distribution; $Y 2_{i}=0$ if otherwise;

3. Low median income $(j): Y 3_{j}=0,1$, where $Y 3_{j}=1$ if the median income of occupation $j$ belongs to the lowest income tercile of occupations' median wage distribution; $Y 3_{j}=0$ if otherwise;

4. High health risk $(j): Y 4_{j}=0,1$, where $Y 4_{j}=1$ if the rate of accidents at work and occupational illnesses $j$ belong to the highest tercile of the distribution; $Y 4_{j}=0$ if otherwise.

Where $i=$ individual with $i=1, \ldots, 85,763$, and $j=$ occupation at 4-digit with $j=1, . ., 487$.

We estimate four univariate probit models, at individual and occupation-level, against the indicator "Working from home" built on the ICP dataset (2012) and a set of covariates expressed in terms of dummies or categorical variables, as described in Table 3. The choice of a parametric model implies the loss of information on potential heterogeneous effects for each population of interest. For example, it might be that the employment risk increases for some particular 4-digit occupations, because of processes of restructuring of the sector of activity. However, being our covariates dummy or categorical variables it is not possible to proceed with non-parametric probit estimations allowing for local effects of the regression coefficients, changing with the intensity of explanatory variables. The diagnostic ability of the four models has been assessed through sensitivity (detection of true positives) and specificity (detection of true negatives) analysis. ROC curves (Fig. 13 in the Appendix) show a positive concave relationship, with areas under the curve always above $70 \%$ which indicate a satisfying diagnostic ability of the model with respect to a random classification.

\subsection{Employment and income risks}

Our first variable of interest is the risk of losing the job for an individual employed in a FH occupation, as a baseline, compared with an individual in a NFH occupation. In order to define the employment risk we look at individual transition events from employment to unemployment or inactivity, from time $t$ (2016) to $t+1$ (2017). ${ }^{17}$ Given the lack of longitudinal panel data at individual level, we are able to capture only yearly based transitions to unemployment, therefore discarding information from longer transition spells. Likely, the baseline transition year, 2016, is not characterised by strong cyclical macroeconomic factors which could have alternatively

\footnotetext{
17 We follow the definition of unemployment provided by ILO which includes unavailable job-seekers in labour force. For recent empirical studies applying this notion of "wide unemployment" see for instance Cassandro et al. (2021).
} 
Table 4 Probit models (individual level data 2016-2017)

\begin{tabular}{|c|c|c|}
\hline & $\begin{array}{l}\text { (1) } \\
\text { Unemployment Risk }\end{array}$ & $\begin{array}{l}\text { (2) } \\
\text { Low Income }\end{array}$ \\
\hline Not From Home & $\begin{array}{l}0.187^{* * *} \\
(5.31)\end{array}$ & $\begin{array}{l}0.374^{* * *} \\
(18.41)\end{array}$ \\
\hline Female & $\begin{array}{l}0.197^{* * *} \\
(7.41)\end{array}$ & $\begin{array}{l}0.749^{* * *} \\
(44.76)\end{array}$ \\
\hline $36-50$ years old & $\begin{array}{l}-0.222^{* * *} \\
(-7.90)\end{array}$ & $\begin{array}{l}-0.257^{* * *} \\
(-13.64)\end{array}$ \\
\hline 50-75 years old & $\begin{array}{l}-0.358^{* * *} \\
(-10.84)\end{array}$ & $\begin{array}{l}-0.448^{* * *} \\
(-21.05)\end{array}$ \\
\hline Lower secondary education level & $\begin{array}{l}0.230^{* * *} \\
(4.67)\end{array}$ & $\begin{array}{l}0.717^{* * *} \\
(24.74)\end{array}$ \\
\hline Secondary education level & $\begin{array}{l}0.0815 \\
(1.80)\end{array}$ & $\begin{array}{l}0.498^{* * *} \\
(18.94)\end{array}$ \\
\hline Bachelor education level & $\begin{array}{l}0.185^{*} \\
(2.52)\end{array}$ & $\begin{array}{l}0.141^{* *} \\
(3.19)\end{array}$ \\
\hline Temporary Contract & $\begin{array}{l}0.780^{* * *} \\
(25.80)\end{array}$ & $\begin{array}{l}0.271^{\text {*** }} \\
(12.11)\end{array}$ \\
\hline Autonomous Contract & $\begin{array}{l}0.0628^{*} \\
(1.97)\end{array}$ & $\begin{array}{l}-1.458^{* * *} \\
(-44.12)\end{array}$ \\
\hline Central Italy & $\begin{array}{l}0.119^{* * *} \\
(3.71)\end{array}$ & $\begin{array}{l}0.145^{* * *} \\
(7.61)\end{array}$ \\
\hline Southern Italy & $\begin{array}{l}0.369^{* * *} \\
(13.97)\end{array}$ & $\begin{array}{l}0.348^{* * *} \\
(20.08)\end{array}$ \\
\hline Agriculture & $\begin{array}{l}-0.236^{* * *} \\
(-3.72)\end{array}$ & $\begin{array}{l}0.671^{* * *} \\
(16.84)\end{array}$ \\
\hline Mining \& Quarrying & $\begin{array}{l}-0.223 \\
(-0.89)\end{array}$ & $\begin{array}{l}0.341^{*} \\
(1.97)\end{array}$ \\
\hline Electricity Gas Water \& Waste & $\begin{array}{l}-0.153 \\
(-1.13)\end{array}$ & $\begin{array}{l}-0.0982 \\
(-1.47)\end{array}$ \\
\hline Construction & $\begin{array}{l}0.280^{* * * *} \\
(5.95)\end{array}$ & $\begin{array}{l}0.182^{* * *} \\
(4.50)\end{array}$ \\
\hline Wholesale Transport \& Accommodation & $\begin{array}{l}0.0602 \\
(1.60)\end{array}$ & $\begin{array}{l}0.451^{* * *} \\
(19.07)\end{array}$ \\
\hline Information \& Communication & $\begin{array}{l}0.0124 \\
(0.12)\end{array}$ & $\begin{array}{l}0.177^{* *} \\
(2.72)\end{array}$ \\
\hline Financial \& Insurance Activities & $\begin{array}{l}-0.301^{*} \\
(-2.16)\end{array}$ & $\begin{array}{l}-0.206^{* *} \\
(-3.22)\end{array}$ \\
\hline Real Estate Activities & $\begin{array}{l}0.298^{*} \\
(2.16)\end{array}$ & $\begin{array}{l}0.573^{\text {**** }} \\
(5.25)\end{array}$ \\
\hline Professional Scientific Support Activities & $\begin{array}{l}0.130^{* *} \\
(2.66)\end{array}$ & $\begin{array}{l}0.790^{* * *} \\
(26.86)\end{array}$ \\
\hline
\end{tabular}


Table 4 (continued)

(1)

Unemployment Risk

$-0.396^{* * *}$

$(-7.56)$

$0.292^{* * *}$

$-2.339^{* * * *}$

82,177

0.124
(2)

Low Income

0.0517

$1.067^{* * *}$

$-2.251^{\text {*** }}$

85,763

0.256

PseudoR $^{2}$

$t$ statistics in parentheses

${ }^{*} p<0.05,{ }^{* *} p<0.01,{ }^{* * *} p<0.001$

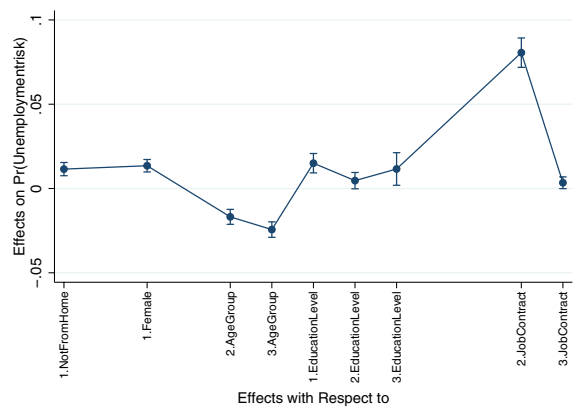

(a) Employment risk

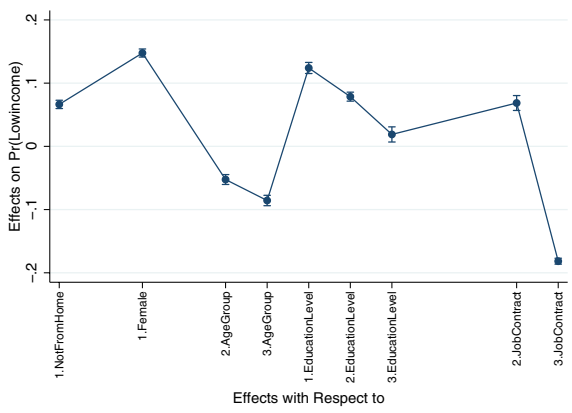

(b) Income risk

Fig. 9 Average marginal effects on employment and low income risks - Regression in Table 4

impacted upon estimation results. Indeed, it was a period of anaemic recovery since the 2008 crisis. Additionally, we are not able to capture persistent unemployment and duration effects.

Table 4 (column 1) presents the probit regression coefficients. Confirming the information from Fig. 8, but now controlling for a comprehensive set of covariates, the variable "Not working from home", shows a positive and significant effect on the probability of transiting to unemployment status for a worker being employed in a NFH occupation as compared to a FH occupation. This positive sign confirms the presence of an inherent higher risk of losing the job, independently from external shocks such as the pandemic, which characterizes those occupations classified as $\mathrm{NFH}$, after controlling for factors such as age, gender, education level and contractual framework. We also observe that being employed in sectors such as Construction, Art and other Services significantly increases the risk of losing the job (with respect to the manufacturing sector), whereas the opposite holds for those working 


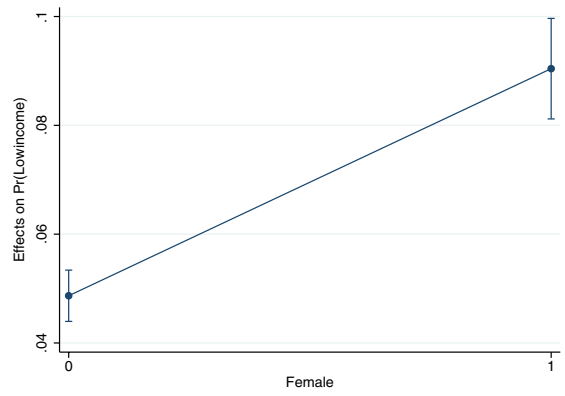

(a) Income risk NFH - Women

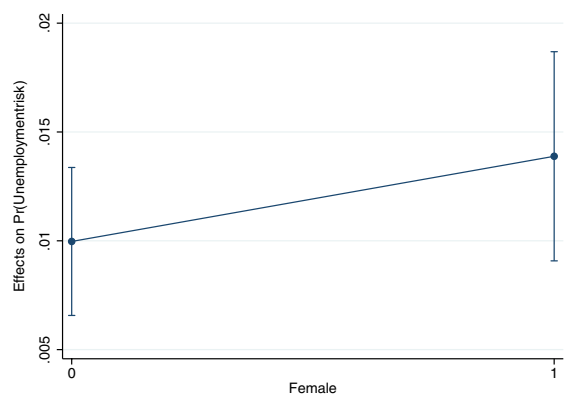

(c) Unemployment risk NFH - Women

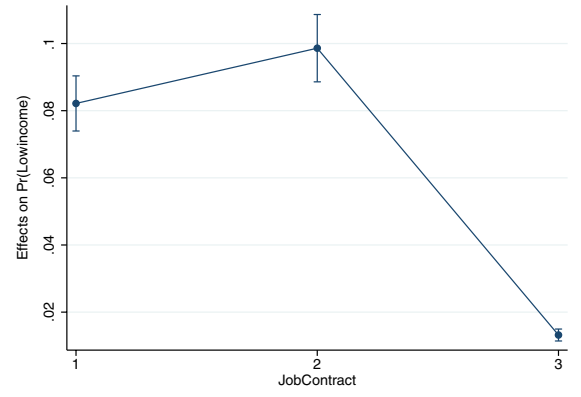

(b) Income risk NFH - Job contract

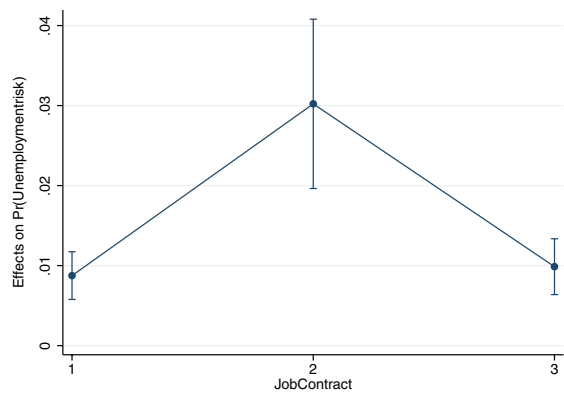

(d) Unemployment risk NFH - Job contract

Fig. 10 Differentiated marginal effects by gender and contractual categories from probit estimates in Table 4

in Public Administration, Education, Health and also Agriculture. Positive and statistically significant coefficients of the two geographical controls confirm the presence of regional disparities in terms of employment security, with workers located in Southern and Central Italy being more exposed to risks of unemployment with respect to their colleagues in the North. ${ }^{18}$

Figure 9, left panel, presents the average marginal effects for NFH occupations. This effect, as expected, turns out to be relatively small (1.1\%) because of the "rare" event we are measuring (one year based transition to unemployment). Other relevant worker attributes which increase the probability of transition to unemployment, or inactive status, are being woman, young and holding a low education title. Indeed, temporary workers experience an employment risk $8 \%$ higher with respect to workers with a permanent contract. In the post lock-down phase, reports on the labour market released by the ISTAT record a huge rise in job losses for temporary workers (ISTAT 2020).

$\overline{18}$ Repeated cross-section estimations are available upon request. 
Our second measure of risk concerns the probability of earning a low income. Income risks are particularly important to be analysed because of the reduced access to work for those individuals who cannot operate from home. Therefore, it is pivotal to understand the pre-existing probabilities of getting a low income whenever a worker employed in a NFH job stops doing its own activity for social distancing measures and related policy regulation. To study the probability of earning a low income, we distinguish among four wage quantiles, namely low, medium-low, medium-high and high. We focus on the low wage quantile.

Table 4, column 2, shows the probit regression coefficients for income risk. The coefficient of the NFH variable is positive and statistically different from zero, implying that belonging to an occupation which cannot be performed remotely inherently increases the probability of earning a low wage. Figure 9, right panel, presents the average marginal effects. The effect of NFH is now sizeable and much bigger than the corresponding one on employment risk (around 6\%). This occurs also because of the higher persistence characterizing the wage distribution, which from year to year tends to show a relatively stable support. With respect to the role played by other covariates, being woman now increases the probability of earning a low income of $15 \%$. Indeed, holding a temporary contract increases the probability of earning a low income of $8 \%$. Also in this case regional disparities are at stage, with workers from Southern and Central Italy recording higher risks of earning a low income. With respect to sectoral heterogeneity, only workers in Finance and Insurance Activities exhibit a lower income risk (compared to the base manufacturing group), as shown by its negative and statistically significant coefficient.

Figure 10 presents differentiated marginal effects by gender and contractual categories highlighting gender divides and the role played by precariousness.

\subsection{Safety risks}

After having identified employment and income risks, we now move toward the estimation of safety risks. To accomplish the latter task, we employ the occupational level dataset ICP-INAIL-ISTAT whose unit of observation is not the individual (as in previous analyses) but the occupation at 4-digit level. More precisely, we investigate whether occupations that cannot be performed from home are more likely to be characterized by a higher health risk (built as the sum of accidents at work and occupational illnesses) and, as robustness check, also by a lower level of income. In order to control for several factors and to be consistent with the previous estimations, we exploit information from the labour force survey to build gender, regional, sectoral, education and contractual dummies. The routine adopted is as such that if $60 \%$ of workers of a given occupation are e.g. female, that occupation is defined as "female dominated", and so on.

According to Table 5, the coefficient of NFH is positive and statistically different from zero in both probit models. This outcome confirms the result obtained in the previous analysis concerning income risk, but it also adds an important information related to the dimension of health and safety at work. Indeed, as shown in Fig. 11, moving from teleworkable to non-teleworkable jobs increases 
Table 5 Probit models (occupational level data 2016)

\begin{tabular}{|c|c|c|}
\hline & $\begin{array}{l}\text { (1) } \\
\text { Low Income }\end{array}$ & $\begin{array}{l}\text { (2) } \\
\text { High Safety Risk }\end{array}$ \\
\hline Not From Home & $\begin{array}{l}0.860^{* * *} \\
(4.54)\end{array}$ & $\begin{array}{l}1.169^{* * *} \\
(4.74)\end{array}$ \\
\hline Female & $\begin{array}{l}1.160^{* * * *} \\
(6.13)\end{array}$ & $\begin{array}{l}-0.445 \\
(-1.95)\end{array}$ \\
\hline Permanent & $\begin{array}{l}-0.565^{* * *} \\
(-3.59)\end{array}$ & $\begin{array}{l}0.459^{* *} \\
(2.61)\end{array}$ \\
\hline Degree & $\begin{array}{l}-1.488^{* * *} \\
(-4.74)\end{array}$ & $\begin{array}{l}-1.378^{* *} \\
(-2.99)\end{array}$ \\
\hline North & $\begin{array}{l}-0.451^{* *} \\
(-2.84)\end{array}$ & $\begin{array}{l}-0.0580 \\
(-0.34)\end{array}$ \\
\hline Agriculture & $\begin{array}{l}1.175^{\text {**** }} \\
(3.48)\end{array}$ & $\begin{array}{l}0.462 \\
(1.38)\end{array}$ \\
\hline Manufacturing & $\begin{array}{l}0.275 \\
(1.37)\end{array}$ & $\begin{array}{l}0.625^{* *} \\
(2.92)\end{array}$ \\
\hline Electricity Gas Water \& Waste & $\begin{array}{l}0.0409 \\
(0.06)\end{array}$ & $\begin{array}{l}1.335^{* *} \\
(2.85)\end{array}$ \\
\hline Construction & $\begin{array}{l}-0.134 \\
(-0.42)\end{array}$ & $\begin{array}{l}0.667^{*} \\
(2.12)\end{array}$ \\
\hline Wholesale Transport \& Accommodation & $\begin{array}{l}0.341 \\
(1.38)\end{array}$ & $\begin{array}{l}0.602^{*} \\
(2.30)\end{array}$ \\
\hline Real Estate Activities & $\begin{array}{l}1.856^{* *} \\
(3.04)\end{array}$ & $\begin{array}{l}0 \\
(.)\end{array}$ \\
\hline Professional Scientific Support Activities & $\begin{array}{l}0.894^{*} \\
(2.41)\end{array}$ & $\begin{array}{l}0.270 \\
(0.67)\end{array}$ \\
\hline Public Administration, Education \& Human Health & $\begin{array}{l}-0.408 \\
(-1.46)\end{array}$ & $\begin{array}{l}0.376 \\
(1.26)\end{array}$ \\
\hline Art \& Other Services & $\begin{array}{l}0.665^{*} \\
(2.16)\end{array}$ & $\begin{array}{l}0.290 \\
(0.84)\end{array}$ \\
\hline _cons & $\begin{array}{l}-0.887^{* * *} \\
(-3.94)\end{array}$ & $\begin{array}{l}-2.140^{* * *} \\
(-6.95)\end{array}$ \\
\hline$N$ & 487 & 485 \\
\hline PseudoR ${ }^{2}$ & 0.307 & 0.237 \\
\hline
\end{tabular}

$t$ statistics in parentheses

${ }^{*} p<0.05,{ }^{* *} p<0.01,{ }^{* * *} p<0.001$

the probability of facing a higher safety risk at work by more than $30 \%$. Clearly, the computed probabilities are much higher than the ones presented in the previous section because in this case the analysis is based on occupational rather than individual level data, increasing by construction the average marginal effects. 


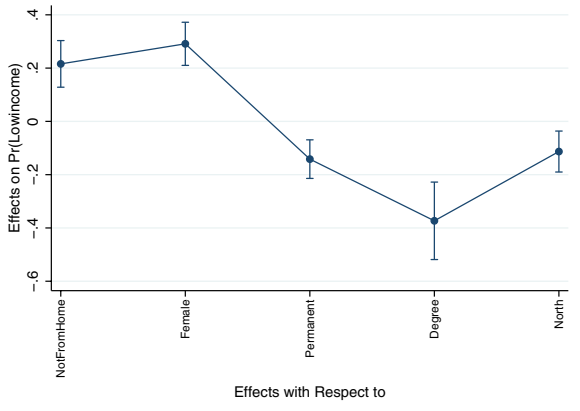

(a) Income risk (robustness check)

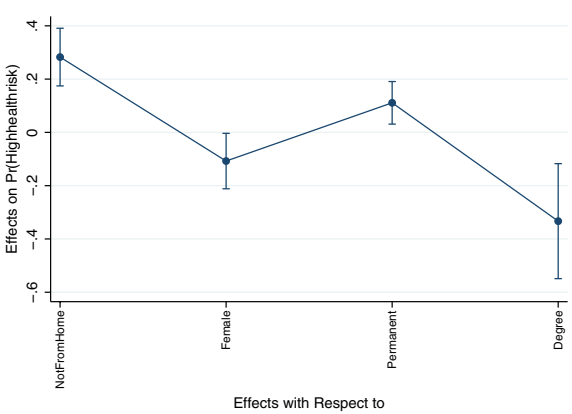

(b) Safety risk at work

Fig. 11 Average marginal effects on low income and health risks from probit estimates in Table 5

Regarding the role played by other covariates, while belonging to a female/temporary contracts dominated profession strongly increases the probability of getting a low income, safety risks are higher in male dominated professions with permanent contracts.

\section{Discussion and conclusions}

With the outbreak of the COVID-19 pandemic, although heterogeneously in terms of timing and intensity, governments opted for social distancing measures directed at reducing interpersonal contacts, the latter being identified as the main source of contagion. In this context, advising or requiring workers to work from home represented one of the key measures included in the "anti-COVID 19" social distancing policy packages (OECD 2020).

Such a pandemic-induced spreading of telework is showing heterogeneous effects on labour market segments: indeed, maintaining full-time working hours and switching to telework represent a suitable option only for a fraction of the working population, belonging to the upper echelon of hierarchies, being employed in occupations not requiring manual and cognitive dexterity, endowed by ICT-knowledge. Therefore, although telework represents an important safety net in terms of health, employment, and income security, it can also turn out into an inequality-enhancing mechanism between those who can and those who cannot work from home.

In this paper, we aimed exactly at assessing the presence of enduring divides between Italian workers that can work from home and those who cannot. This distinction, grounded on the study of occupational characteristics and their telework feasibility, turns out to be revealing of stratifying vulnerabilities in terms of income remuneration, employment stability and safety at work. Our results show that NFH workers record higher probabilities of earning a low income, losing job, experiencing accidents at work and occupational illnesses with respect to FH workers. Women and temporary workers face stratifying and conflating risks. 
Indeed, first available statistics confirm the higher incidence of job losses among NFH and precarious workers (see, for instance, Guven et al. (2020) for Australia; Montenovo et al. (2020) for USA; Adams-Prassl et al. (2020a) for the UK). All this couples with a stagnant labour demand in teleworkable occupations, almost concentrated in the North of Italy. As a consequence, labour and social protection policies should aim at reducing rather than exacerbating those divides, starting with flexible shifts, extension of sick leaves, full-paid paternal and maternal leaves, secure income stability. At the same time, fostering social dialogue and promoting the adoption of effective health and safety protocols through the direct involvement of workers and trade unions is crucial (ILO 2020).

One limitation of our results is the lack of information about firms strategic orientation on telework. Indeed, between-firm variability might count as much as between-occupational variability. According to the annual report by the ISTAT, ${ }^{19}$ conducting a survey on firms strategic behaviour under the pandemic (repeated sample, two waves May-October 2020), Italian firms switching to telework have done so in a temporary manner, although remarkably rising the overall share of teleworking activities when compared to the pre-pandemic phase. However, the fraction of workers performing their activity from home never exceeded $35 \%$ and only with reference to large firms. Considering all firms, this figure drops to $15 \%$ on average over the year (2020). Clearly, size and sectoral dimensions are crucial in affecting such variability. What is remarkable is that, independently from sectoral heterogeneity, firms tended to reduce the fraction of teleworking positions after emergency phases. Additionally, the few second-level collective agreements regulating smart-working ${ }^{20}$ clearly distinguish those job titles and those productive units that can perform activities remotely from those that cannot at all.

At this stage, firms attitude and satisfaction toward teleworking as a durable preferable option, whenever viable, is still unclear. When discussing about telework, we need to distinguish between telework as an organizational option and telework as the only choice. In the first case, it should be conceived as part of a policy strategy pushing for shorter and more flexible working time, preventing and limiting all the documented side effects, such as increasing work intensification and unpaid overtime, difficulties in balancing working and private life and risk of burnout, being only some of the drawbacks reported by workers (Messenger 2019), by means of contractual regulations. Second, given the lack of conclusive evidence on firm performances, on the processes of knowledge diffusion, on creativity, on collaborative practices among workers, a complete switch to telework is not advisable as well.

A second limitation of our study regards the use of cross-sectional information of the ICP dating back to 2012. However, longitudinal analyses on contents of occupations are currently not feasible for Italy, due to the lack of data availability, and just starting for the US (Freeman et al. 2020), albeit in this case confirming a quite stable dynamics of within-occupational variation over ten years (2005-2015) of many of the variables analysed.

\footnotetext{
${ }^{19}$ Available here: https://www.istat.it/storage/rapporto-annuale/2021/Capitolo_4.pdf.

${ }^{20}$ Available here: https://www.cnel.it/Archivio-Contratti/Covid-Contrattazione-settoriale-nazionale-e-integ rativa.
} 
Being the aim of the paper to look at (i) the structural determinants of occupations to access to telework, (ii) the distribution of teleworking along hierarchical layers, sectors, geographical areas and gender, (iii) the risks connected to the impossibility of working from home whenever required by eventual external conditions, our results might be of support to design policy interventions, beyond emergency conditions, able to promote a sustainable, durable, coexistence with teleworking. Our analysis should help in understanding that a massive transition toward teleworking is nowadays unfeasible given the extant productive structure largely employing occupations requiring in person presence. In fact, the Italian labour market includes a non-negligible share of young, non-standard and precarious workers facing higher employment, income and safety risks compared to the rest of the workforce. These workers are now further penalized by the inaccessibility to telework as a mean to safeguard their occupation and income. Additionally, lay-offs in the pandemic phase have shown the dramatic lack of an adequate social protection legislation, in terms of both unemployment subsidies and job retention schemes (Guarascio 2021). A stronger and stable welfare support for the most fragile segments should be designed taking into account the additional risk stratification represented by the uneven teleworkability of occupations.

Future lines of research entail the study of heterogeneity across teleworkers, in terms of occupational categories, sectors of activity and employer characteristics. What is more, if telework will essentially turn into working from home, availability of adequate private spaces, responsibility of looking after kids and doing houseworks will strongly influence the overall consequences of telework across hierarchical positions and gender.

\section{Appendix}

\section{Descriptive figures on NFH/FH jobs}

See Table 6, Fig. 12, Table 7, and Fig. 13

\section{Stratification of risks}

See Tables 8, 9, 10 and 11 . 
Table 6 Variables used to build the Not from home index

\section{Question}

H.17 How often does your profession require you to work outdoors exposed to all weather conditions?

H.18 How often does your profession require you to work outdoors but sheltered (like in an open shack)?

H.19 How often does your profession require you to work in a piece of equipment or an open vehicle (such as a tractor)?

H.20 How often does your profession require you to work in closed equipment or vehicle (such as a machine)?

H.27 How often in your work are you exposed to vibrations throughout your body (such as when operating a jackhammer or bulldozer)?

H.32 How often does your work require you to expose yourself to dangerous equipment (such as working with saws, near machines with moving parts or vehicles)?

H.40 In your work, how long do you use your hands to manipulate, control or feel objects, tools or control systems?

H.43 In your work, how long do you wear protective or safety equipment such as shoes, glasses, gloves, earplugs, helmets or jackets?

H.44 In your work, how long do you wear specialist protective or safety equipment such as self-contained breathing apparatus, harnesses, full protective suits or radiation protection clothing?

H.55 How important is it in your work to keep sequences of machinery and equipment under control?

G.18 Managing machines and processes

G.20 Maneuvering vehicles, vehicles and equipment

G.22 Repair and maintain equipment

G.23 Repairing and maintaining electronic equipment

G.4 Inspect equipment, structures or materials

H.25 How often are you exposed to contaminants (such as polluting gases or dust) in your work?

H.28 How often does your work require you to be exposed to radiation? (This may happen, for example, to people working in chemistry or radiology laboratories)

H.29 How often does your work require you to expose yourself to disease or infection? (This may happen, for example, to people working in hospitals, or in medical or analytical laboratories, or to those engaged in disinfection activities)

H.31 How often does your work require you to expose yourself to hazardous situations (such as working with high voltage electricity, flammable materials, explosives or chemicals)?

H.33 How often does your work require you to expose yourself to small burns, small cuts, bites, stings?
Category

Outdoor activities

Outdoor activities

Outdoor activities

Use of machine or specific equipment

Use of machine or specific equipment

Use of machine or specific equipment

Use of machines or specific equipment

Use of machines or specific equipment

Use of machines or specific equipment

Use of machines or specific equipment

Use of machines or specific equipment Use of machines or specific equipment Use of machines or specific equipment Use of machines or specific equipment Use of machines or specific equipment

Bio-chemical risk exposure

Bio-chemical risk exposure

Bio-chemical risk exposure

Bio-chemical risk exposure

Bio-chemical risk exposure 
Table 6 (continued)

Question Category

H.30 How often does your work require you to expose yourself

Highly Physical or manual activities in places or places high above the ground (such as working on poles, scaffolding, stairs, walkways higher than $2.5 \mathrm{~m}$ )?

H.35 In your work, how long do you climb ladders, poles, scaf- Highly Physical or manual activities folding, etc.?

H.36 How long do you walk or run in your work? (excluding home-work trips)

H.37 In your work how long do you kneel, crouch, crawl, crawl or bend?

H.38 How long in your work do you maintain or recover your balance?

G.16 Perform physical activities that require moving the entire body, or considerable use of arms and legs (such as climbing stairs, balancing, walking, bending and handling materials)

G.17 Handling and moving objects

G.29 Assisting and caring for others

Highly Physical or manual activities

Social contact

G.32 Working in direct contact with the audience and performing

Social contact

H.4 How often does your profession require the use of e-mail?

E-mail Use 


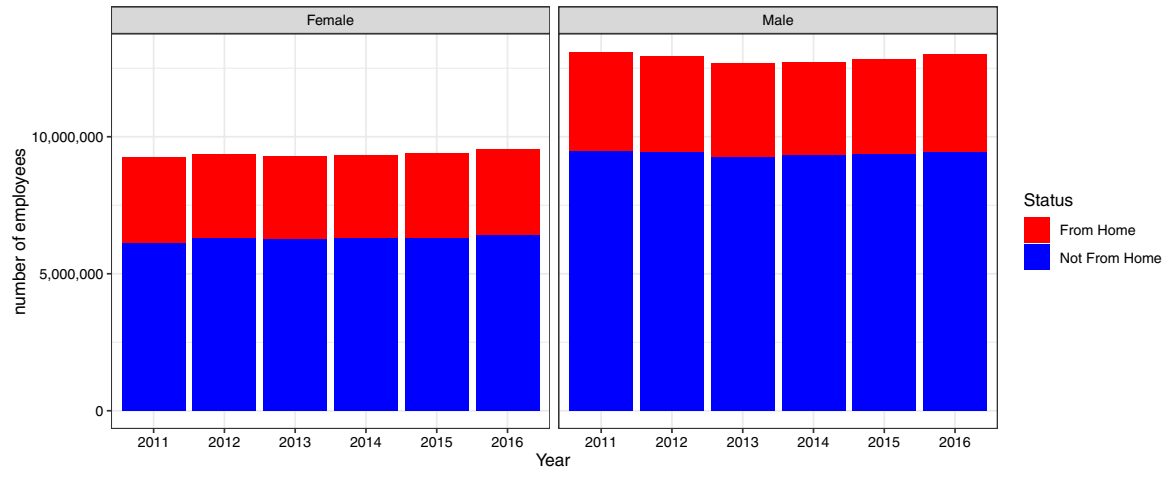

(a) Total workers

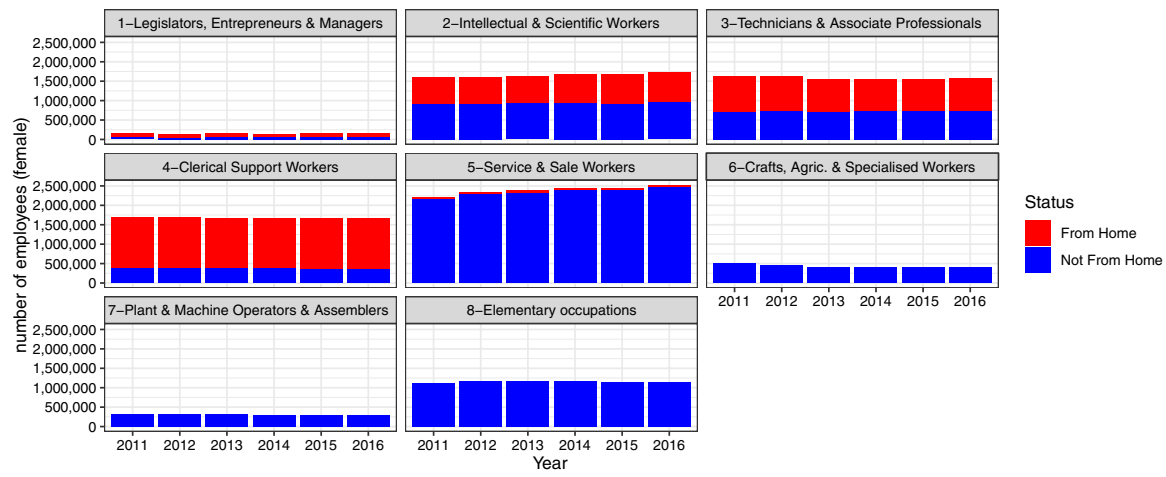

(b) Female workers

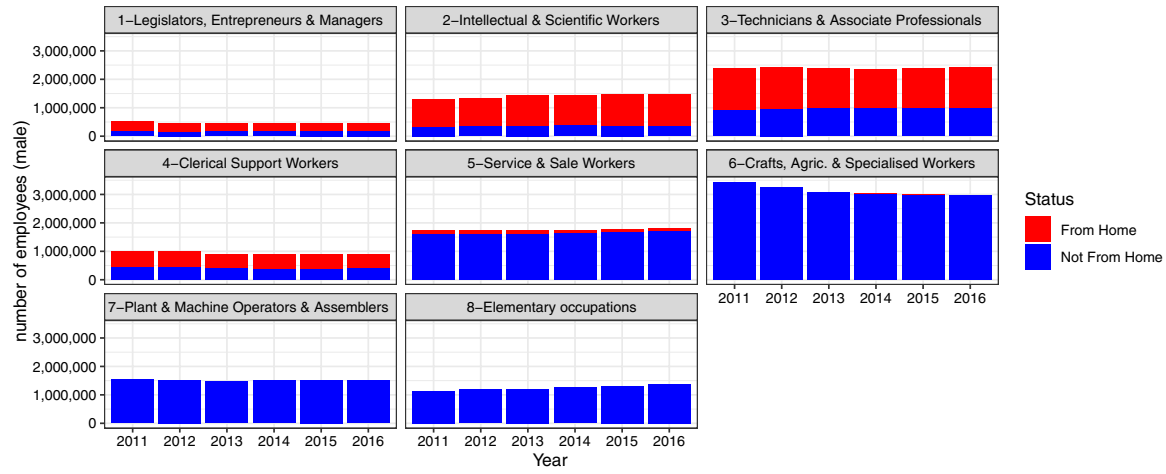

(c) Male workers

Fig. 12 Total and gender distribution at 1-digit (ISCO classification) for employees which can and cannot work from home. Source: ICP-RCFL (2011-2016) 
Table 7 Top-ten female-dominated occupations which can and cannot be performed from home (3-digit, ISCO classification). Source: ICP-ILFS (2016)

Top-ten female dominated occupations which can be performed from home

Female

workers

(share)

112 Directors, executives and equivalent in public administration and in health, education and research services

411 Secretarial and general affairs clerks

265 Other education and training specialists

432 Clerical, accounting and financial management employees

82

412 Office machine employees

69

422 Employees in charge of welcoming and informing clients

68

113 Magistrate Directors

68

331 Technicians in the organisation and administration of production activities

66

346 Public service and security technicians

66

513 Other qualified professions in commercial activities

65

441 Employees in charge of checking documents and sorting and delivering mail

61

Top-ten female dominated occupations which cannot be performed from home

Female

workers

(share)

264 Primary and pre-primary school teachers and similar professions

345 Social services technicians

822 Unqualified personnel in charge of domestic services

531 Qualified professions in health and social services

545 Animal trainers and keepers

321 Health technicians

231 Specialists in life sciences

541 Masters of arts and crafts

523 Travel assistants and similar professions 


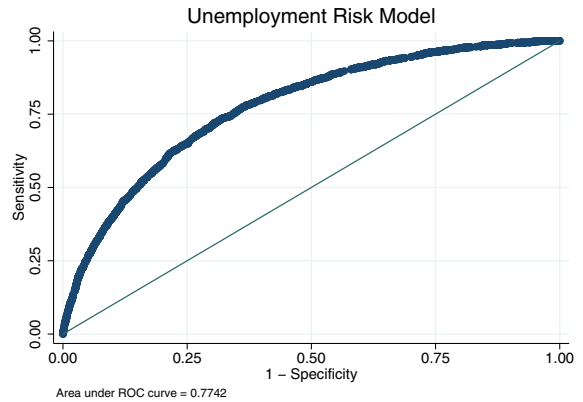

(a) ROC Curve - Unemployment Risk Model

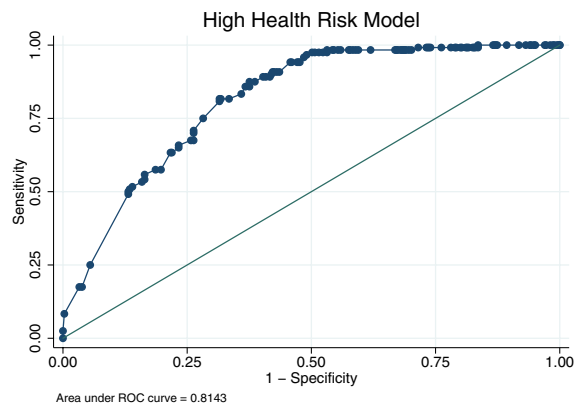

(c) ROC Curve - High Health Risk Model

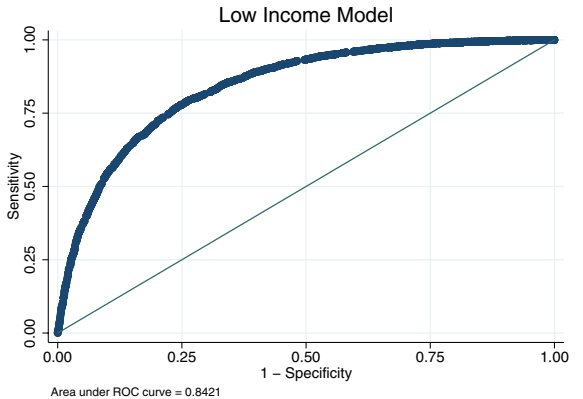

(b) ROC Curve - Low Income Risk Model

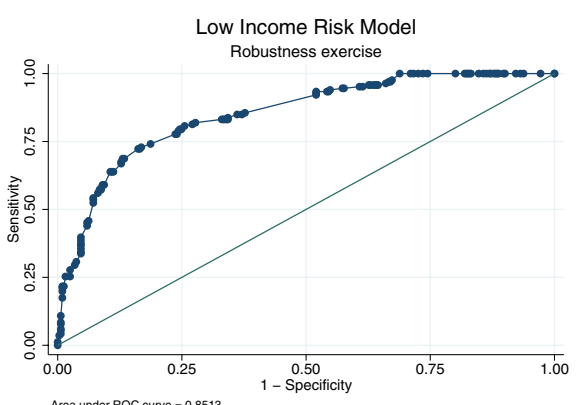

(d) ROC Curve - Low Income Risk Model (occupations)

Fig. 13 Model diagnostic (ROC Curves)

\section{Robustness checks}

In the following, we perform a series of robustness checks comparing alternative available indicators, alternative constructions of our indicator, and their effects in terms of econometric estimations. Finally, we also perform a factor analysis to detect the extent to which the selected variables to construct the indicator present some latent factors.

\section{Comparison across indicators of teleworkability}

The literature has proposed several indicators of teleworkability both of discrete and continuous types: while discrete indicators capture the divide between FH/NFH occupations and attributes of teleworkability, continuous indicators are more apt to study the intensity of teleworkability. In order to test the validity of our indicator, we proceed with a number of robustness checks. First, we compare our indicator with the one proposed by Dingel and Neiman (2020), the first contribution introducing an empirical methodology based on the O*NET database in order to understand potential access to telework for the US workforce. The methodology has subsequently been adopted in numerous studies on advanced and developing economies (Saltiel 2020). 
Table 8 Occupations recording the co-occurrence of low income risk, unemployment risk (based on individual level data) and health risk (based on occupation data)

\begin{tabular}{|c|c|c|c|}
\hline 4 Digit code & Status & Occupation & Female $\%$ \\
\hline 3413 & NFH & Tourist entertainers and similar professions & 56.8 \\
\hline 3427 & $\mathrm{NFH}$ & Athletes & 5.66 \\
\hline 5122 & $\mathrm{NFH}$ & Retail sales assistants & 67.84 \\
\hline 5221 & $\mathrm{NFH}$ & Cooks in hotels and restaurants & 28.9 \\
\hline 5222 & $\mathrm{NFH}$ & Food preparation, cooking and distribution personnel & 72.1 \\
\hline 5223 & $\mathrm{NFH}$ & Waiters and similar professions & 60.9 \\
\hline 5472 & $\mathrm{NFH}$ & Funeral parlour attendants & 8.3 \\
\hline 5486 & $\mathrm{NFH}$ & Private security guards & 11.2 \\
\hline 5487 & $\mathrm{NFH}$ & Lifeguards and similar professions & 14.9 \\
\hline 6112 & $\mathrm{NFH}$ & Stone cutters, stonemasons and stonemasons & 1.2 \\
\hline 6123 & $\mathrm{NFH}$ & $\begin{array}{l}\text { Carpenters and carpenters in the building industry (excluding parking } \\
\text { lots) }\end{array}$ & 0.50 \\
\hline 6133 & $\mathrm{NFH}$ & Plasterers & 0 \\
\hline 6216 & $\mathrm{NFH}$ & Divers and diving workers & 0 \\
\hline 6221 & $\mathrm{NFH}$ & Blacksmiths, ingotters and press operators for forging & 1.02 \\
\hline 6332 & $\mathrm{NFH}$ & Artisans of handmade textiles, leather and the like & 52.3 \\
\hline 6413 & NFH & Farmers and farm workers specialising in gardens and nurseries & 15 \\
\hline 6441 & $\mathrm{NFH}$ & Specialised forestry workers & 0 \\
\hline 6452 & $\mathrm{NFH}$ & Inshore and inland fisheries fishermen & 1.15 \\
\hline 6531 & $\mathrm{NFH}$ & Fibre preparers & 28.1 \\
\hline 6532 & $\mathrm{NFH}$ & Weavers and knitters by hand and on manual looms & 52.4 \\
\hline 7275 & $\mathrm{NFH}$ & Assemblers in series of articles in wood and similar materials & 28.3 \\
\hline 7281 & $\mathrm{NFH}$ & Industrial product packaging machine workers & 54.7 \\
\hline 7328 & $\mathrm{NFH}$ & Industrial winemakers and brewers & 6.3 \\
\hline 7421 & $\mathrm{NFH}$ & Taxi drivers, drivers of cars, vans and other vehicles & 4.6 \\
\hline 7431 & $\mathrm{NFH}$ & Agricultural tractor drivers & 0.54 \\
\hline 8131 & $\mathrm{NFH}$ & Porters, goods handlers and similar & 7.3 \\
\hline 8132 & $\mathrm{NFH}$ & Unqualified packaging and warehouse staff & 21 \\
\hline 8133 & NFH & Delivery staff & 7.6 \\
\hline 8141 & $\mathrm{NFH}$ & Unqualified cleaning staff in accommodation services and ships & 66.6 \\
\hline 8142 & $\mathrm{NFH}$ & Personnel not qualified in catering services & 60.8 \\
\hline 8143 & NFH & Unqualified staff in charge of cleaning services in offices and shops & 73.9 \\
\hline 8145 & $\mathrm{NFH}$ & Green operators and other waste collectors and separators & 7.1 \\
\hline 8311 & NFH & Farm labourers & 32 \\
\hline 8312 & $\mathrm{NFH}$ & Unqualified green maintenance personnel & 5.7 \\
\hline 8321 & $\mathrm{NFH}$ & Unqualified forestry personnel & 11.3 \\
\hline 8411 & $\mathrm{NFH}$ & Maneuvers and other unskilled personnel from mines and quarries & 0 \\
\hline 8421 & $\mathrm{NFH}$ & $\begin{array}{l}\text { Skilled workers and unskilled civil construction workers and similar } \\
\text { professions }\end{array}$ & 0.53 \\
\hline 8422 & NFH & Construction and maintenance of roads, dams and other public works & 2.05 \\
\hline 8431 & $\mathrm{NFH}$ & Unqualified personnel from industrial activities and similar professions & 35.7 \\
\hline
\end{tabular}


Table 9 Occupations recording the co-occurrence of low income risk and unemployment risk (based on micro data)

\begin{tabular}{|c|c|c|c|}
\hline 4-Digit code & Status & Occupation & Female $\%$ \\
\hline 2655 & NFH & Teachers of artistic and literary disciplines & 80.5 \\
\hline 3216 & NFH & Other technical health professions & 11.4 \\
\hline 3333 & NFH & Commissioners, evaluators and commercial auctioneers & 71.7 \\
\hline 3414 & $\mathrm{NFH}$ & Travel agents & 71 \\
\hline 3423 & $\mathrm{NFH}$ & Instructors of techniques in the artistic field & 85.2 \\
\hline 3424 & $\mathrm{NFH}$ & Non-competitive sports instructors & 47.7 \\
\hline 3452 & $\mathrm{NFH}$ & Reintegration and social integration technicians & 74 \\
\hline 4216 & $\mathrm{NFH}$ & Travel agency counter clerks & 90.3 \\
\hline 4222 & $\mathrm{NFH}$ & Receptionists in accommodation and catering services & 51.8 \\
\hline 4224 & $\mathrm{NFH}$ & Information officers in Call Centres (without sales functions) & 78.3 \\
\hline 5124 & $\mathrm{NFH}$ & Cashiers of commercial establishments & 85.4 \\
\hline 5224 & $\mathrm{NFH}$ & Barmen and similar professions & 59.9 \\
\hline 5231 & $\mathrm{NFH}$ & Hostesses, stewards and similar professions & 71.2 \\
\hline 5232 & NFH & Tourist guides & 65.6 \\
\hline 5422 & $\mathrm{NFH}$ & Bookmakers, croupiers and similar professions & 35 \\
\hline 5431 & $\mathrm{NFH}$ & Hairdressers & 66 \\
\hline 5432 & $\mathrm{NFH}$ & Beauticians and make-up artists & 94 \\
\hline 5442 & NFH & Supervisors of children and similar professions & 90.4 \\
\hline 5443 & $\mathrm{NFH}$ & Personal care workers & 90.5 \\
\hline 5452 & $\mathrm{NFH}$ & Keepers and breeders of pets and show animals & 47.3 \\
\hline 6215 & NFH & $\begin{array}{l}\text { Equipment and assemblers of metal cables for industrial and transport } \\
\text { use }\end{array}$ & 0 \\
\hline 6453 & $\mathrm{NFH}$ & Deep sea fishermen & 0 \\
\hline 6512 & $\mathrm{NFH}$ & Artisan bakers and pasta makers & 22.5 \\
\hline 6513 & $\mathrm{NFH}$ & Confectioners, ice-cream makers and artisan canners & 41.3 \\
\hline 6533 & $\mathrm{NFH}$ & Artisan tailors and cutters, modellers and hatters & 82.3 \\
\hline 6535 & $\mathrm{NFH}$ & Whiteworkers, hand embroiderers and similar professions & 86.2 \\
\hline 6536 & $\mathrm{NFH}$ & Upholsterers & 35.4 \\
\hline 6542 & $\mathrm{NFH}$ & Craftsmen and skilled workers of footwear and similar products & 40.8 \\
\hline 6543 & NFH & Suitcases, handbags and similar professions & 63.2 \\
\hline 7151 & $\mathrm{NFH}$ & Conductors of oil product refining plants & 0 \\
\hline 7267 & NFH & Shoe series production machinery operators & 34.2 \\
\hline 7324 & $\mathrm{NFH}$ & Machinery operators for the treatment and conservation of food & 75.2 \\
\hline 8161 & $\mathrm{NFH}$ & $\begin{array}{l}\text { Unqualified personnel in charge of building and goods custody } \\
\text { services }\end{array}$ & 25.4 \\
\hline 8211 & NFH & Unqualified personnel in recreational and cultural services & 36.5 \\
\hline 8221 & $\mathrm{NFH}$ & Domestic workers and similar professions & 88.8 \\
\hline 8322 & $\mathrm{NFH}$ & Unqualified animal care staff & 21.7 \\
\hline 3442 & $\mathrm{FH}$ & Museum technicians, libraries and similar professions & 78.8 \\
\hline 4111 & $\mathrm{FH}$ & Secretarial staff & 87.9 \\
\hline 4121 & $\mathrm{FH}$ & Video-writers, typists, stenographers and similar professions & 69 \\
\hline 4122 & FH & Data entry officers & 57.9 \\
\hline
\end{tabular}


Table 9 (continued)

\begin{tabular}{llll}
\hline 4-Digit code & Status & Occupation & Female \% \\
\hline 4215 & FH & Ticket sales staff & 53.6 \\
4321 & FH & Accountants & 81.7 \\
4324 & FH & Statistical services employees & 65.2 \\
4422 & FH & Employees in libraries and similar professions & 64.8 \\
5125 & FH & Home and distance sellers and similar professions & 64.1 \\
\hline
\end{tabular}

Table 10 Occupations recording the co-occurrence of low income risk (individual data) and health risk (occupation data)

\begin{tabular}{|c|c|c|c|}
\hline 4-Digit code & Status & Occupation & Female $\%$ \\
\hline 3215 & $\mathrm{NFH}$ & Technical professions of prevention & 60 \\
\hline 4312 & $\mathrm{NFH}$ & Warehouse management and similar professions & 21.2 \\
\hline 4412 & $\mathrm{NFH}$ & Travel documentation checkers & 25 \\
\hline 5311 & $\mathrm{NFH}$ & Qualified professions in health and social services & 82 \\
\hline 5481 & $\mathrm{NFH}$ & Territorial guardianship staff & 1.47 \\
\hline 6111 & $\mathrm{NFH}$ & Brillators (blastingers) & 0 \\
\hline 6151 & $\mathrm{NFH}$ & Workers in charge of hygiene and cleaning services & 46.7 \\
\hline 6234 & $\mathrm{NFH}$ & Refrigerators & 5.1 \\
\hline 6324 & $\mathrm{NFH}$ & Painters and decorators on glass and ceramics & 48 \\
\hline 6331 & $\mathrm{NFH}$ & Artisans of artistic woodworking and assimilated materials & 12.4 \\
\hline 6414 & $\mathrm{NFH}$ & Farmers and specialized agricultural workers of mixed crops & 32 \\
\hline 6511 & $\mathrm{NFH}$ & Butchers, fishmongers and similar professions & 15 \\
\hline 6515 & $\mathrm{NFH}$ & Craftsmen and workers specialized in dairy craftsmanship & 19.5 \\
\hline 6521 & $\mathrm{NFH}$ & Craftsmen and workers specialized in wood treatment & 23.9 \\
\hline 6523 & $\mathrm{NFH}$ & $\begin{array}{l}\text { Strippers, basket makers, sweepers, cork-blowers and similar profes- } \\
\text { sions }\end{array}$ & 19.5 \\
\hline 7131 & $\mathrm{NFH}$ & Plant operators for the production of glass, ceramics and bricks & 18.2 \\
\hline 7241 & $\mathrm{NFH}$ & $\begin{array}{l}\text { Machinery workers in plants for the mass production of furniture and } \\
\text { wooden articles }\end{array}$ & 12.7 \\
\hline 7312 & $\mathrm{NFH}$ & Olive processing plant workers & 7.6 \\
\hline 7313 & $\mathrm{NFH}$ & $\begin{array}{l}\text { Workers in charge of refrigeration, hygienic treatment and first pro- } \\
\text { cessing of milk }\end{array}$ & 3.3 \\
\hline 7322 & $\mathrm{NFH}$ & $\begin{array}{l}\text { Conductors of equipment for the industrial processing of dairy prod- } \\
\text { ucts }\end{array}$ & 31.3 \\
\hline 7325 & $\mathrm{NFH}$ & Sugar production and refining machine operators & 11.4 \\
\hline 7413 & $\mathrm{NFH}$ & Ropeway operators & 0 \\
\hline 8121 & $\mathrm{NFH}$ & Ushers and similar professions & 24.8 \\
\hline 8122 & $\mathrm{NFH}$ & Meter readers, coin collectors and similar professions & 5.2 \\
\hline 8144 & $\mathrm{NFH}$ & Vehicle washers & 3.2 \\
\hline 8151 & $\mathrm{NFH}$ & Bidels and assimilated professions & 67.8 \\
\hline 8152 & $\mathrm{NFH}$ & Porters and similar professions & 66.8 \\
\hline 5121 & $\mathrm{FH}$ & Wholesale shop assistants & 20 \\
\hline
\end{tabular}


Table 11 Occupations recording the co-occurrence of unemployment risk (individual data) and health risk (occupation data)

\begin{tabular}{|c|c|c|c|}
\hline $\begin{array}{l}4- \\
\text { Digit } \\
\text { code }\end{array}$ & Status & Occupation & $\begin{array}{l}\text { Female } \\
\%\end{array}$ \\
\hline 4413 & $\mathrm{NFH}$ & Mail sorting and delivery staff & 38.2 \\
\hline 6121 & $\mathrm{NFH}$ & Stone, brick, refractory bricklayers & 0.09 \\
\hline 6122 & $\mathrm{NFH}$ & Reinforced concrete masonry workers & 0.59 \\
\hline 6124 & $\mathrm{NFH}$ & Scaffolders & 0 \\
\hline 6125 & $\mathrm{NFH}$ & Tunnel owners, railway equipment operators and similar professions & 0 \\
\hline 6126 & $\mathrm{NFH}$ & Road pavers and similar professions & 0 \\
\hline 6127 & $\mathrm{NFH}$ & Prefabricated and pre-formed products assemblers & 0.98 \\
\hline 6132 & $\mathrm{NFH}$ & Floor and wall tile installers & 0.64 \\
\hline 6135 & $\mathrm{NFH}$ & Glassmakers & 4.1 \\
\hline 6136 & $\mathrm{NFH}$ & Hydraulics and gas and hydraulic piping installers & 0.58 \\
\hline 6137 & $\mathrm{NFH}$ & Electricians in civil construction and similar professions & 0.16 \\
\hline 6138 & $\mathrm{NFH}$ & Window and door and window installers & 0.27 \\
\hline 6141 & $\mathrm{NFH}$ & Painters, plasterers, lacquers and decorators & 2.4 \\
\hline 6152 & $\mathrm{NFH}$ & Sewerage maintenance workers and similar professions & 0 \\
\hline 6213 & $\mathrm{NFH}$ & Sheet metal workers and boilermakers, including tracers & 1.1 \\
\hline 6214 & $\mathrm{NFH}$ & Metal carpentry fitters & 1.2 \\
\hline 6218 & $\mathrm{NFH}$ & Ironworkers & 2.7 \\
\hline 6235 & $\mathrm{NFH}$ & $\begin{array}{l}\text { Mechanics and assemblers of industrial thermal, plumbing, air conditioning } \\
\text { equipment }\end{array}$ & 1.4 \\
\hline 6244 & $\mathrm{NFH}$ & Installers and repairers of telecommunications equipment & 0 \\
\hline 6342 & $\mathrm{NFH}$ & Offset and press printers & 19.4 \\
\hline 6522 & $\mathrm{NFH}$ & Woodworking machine carpenters and toolmakers & 1.5 \\
\hline 6541 & $\mathrm{NFH}$ & Leather and fur tanners & 11 \\
\hline 6551 & $\mathrm{NFH}$ & Stage machinists and toolmakers & 0 \\
\hline 7123 & NFH & Metal heat treatment plant operators & 4.4 \\
\hline 7134 & $\mathrm{NFH}$ & $\begin{array}{l}\text { Kiln drivers and other plants for the production of bricks, tiles and similar } \\
\text { products }\end{array}$ & 5.5 \\
\hline 7153 & $\mathrm{NFH}$ & Operators of machinery for the manufacture of chemical derived products & 17.4 \\
\hline 7212 & NFH & Machinery workers for the production of cement and similar products & 0 \\
\hline 7233 & NFH & Machinery operators for the manufacture of plastic and similar products & 21.9 \\
\hline 7279 & $\mathrm{NFH}$ & $\begin{array}{l}\text { Other workers involved in the assembly and mass production of industrial } \\
\text { items }\end{array}$ & 22.1 \\
\hline 7423 & $\mathrm{NFH}$ & HGV and truck drivers & 0.64 \\
\hline 7432 & $\mathrm{NFH}$ & Harvesting, harvesting, harvesting, chopping and pressing machine operators & 12.7 \\
\hline 7441 & $\mathrm{NFH}$ & Earthmoving machinery drivers & 0 \\
\hline 6514 & $\mathrm{FH}$ & Food and beverage tasters and classifiers & 68.5 \\
\hline
\end{tabular}


Table 12 Comparison between Dingel and Neiman (2020) and Cetrulo et al. (2020)

\begin{tabular}{|c|c|}
\hline Dingel and Neiman (2020) & Cetrulo et al. (2020) \\
\hline $\begin{array}{l}\text { H.17 How often does your current job require } \\
\text { you to work outdoors, exposed to all weather } \\
\text { conditions }\end{array}$ & Yes \\
\hline $\begin{array}{l}\text { H.18 How often does your current job require you } \\
\text { to work outdoors, under cover (like in an open } \\
\text { shed)? }\end{array}$ & Yes \\
\hline No & $\begin{array}{l}\text { H.19 How often does your profession require you to } \\
\text { work in a piece of equipment or an open vehicle } \\
\text { (such as a tractor)? }\end{array}$ \\
\hline No & $\begin{array}{l}\text { H.20 How often does your profession require you } \\
\text { to work in closed equipment or vehicle (such as a } \\
\text { machine)? }\end{array}$ \\
\hline No & $\begin{array}{l}\text { H.27 How often in your work are you exposed to } \\
\text { vibrations throughout your body (such as when } \\
\text { operating a jack hammer or bulldozer)? }\end{array}$ \\
\hline No & $\begin{array}{l}\text { H.32 How often does your work require you to } \\
\text { expose yourself to dangerous equipment (such as } \\
\text { working with saws, near machines with moving } \\
\text { parts or vehicles)? }\end{array}$ \\
\hline No & $\begin{array}{l}\text { H.40 In your work, how long do you use your hands } \\
\text { to manipulate, control or feel objects, tools or } \\
\text { control systems? }\end{array}$ \\
\hline
\end{tabular}

H.43 In your current job, how often do you wear common protective or safety equipment such as safety shoes, glasses, gloves, hearing protection, hard hats, or life jackets?

Q.44 In your current job, how often do you wear specialized protective or safety equipment, such as breathing apparatus, safety harness, full protection suits, or radiation protection?

No

Yes

Yes

H.55 How important is it in your work to keep sequences of machinery and equipment under control?

G.18 Controlling machines and processes

Yes

G.20 Operating vehicles, mechanized devices or equipment

G.22 Repairing and maintaining mechanical equipment

G.23 Repairing and maintaining electronic equipment

G.4 Inspecting equipment, structures or materials

No

Yes

Yes

Yes

Yes

H.25 How often are you exposed to contaminants (such as polluting gases or dust) in your work?

No

H.28 How often does your work require you to be exposed to radiation?

H.29 How often does your current job require that Yes you be exposed to diseases or infection? This can happen with workers in patient care, some laboratory work,sanitation control, etc 
Table 12 (continued)

\begin{tabular}{|c|c|}
\hline Dingel and Neiman (2020) & Cetrulo et al. (2020) \\
\hline No & $\begin{array}{l}\text { H.31 How often does your work require you to } \\
\text { expose yourself to hazardous situations? }\end{array}$ \\
\hline $\begin{array}{l}\text { H.33 How often does your current job require that } \\
\text { you be exposed to minor burns, cuts, bites, or } \\
\text { stings? }\end{array}$ & Yes \\
\hline No & $\begin{array}{l}\text { H.30 How often does your work require you to } \\
\text { expose yourself in places or places high above the } \\
\text { ground? }\end{array}$ \\
\hline No & $\begin{array}{l}\text { H.35 In your work, how long do you climb ladders, } \\
\text { poles, scaffolding, etc.? }\end{array}$ \\
\hline No & $\begin{array}{l}\text { H.36 How long do you walk or run in your work? } \\
\text { (excluding home-work trips) }\end{array}$ \\
\hline $\begin{array}{l}\text { H.37 How much time in your current job do you } \\
\text { spend walking or running? }\end{array}$ & Yes \\
\hline No & $\begin{array}{l}\text { H.38 How long in your work do you maintain or } \\
\text { recover your balance? }\end{array}$ \\
\hline G.16 Performing General Physical Activities & Yes \\
\hline G.17 Handling and moving objects & Yes \\
\hline No & G.29 Assisting and caring for others \\
\hline $\begin{array}{l}\text { G.32 Performing or working directly with the } \\
\text { public }\end{array}$ & Yes \\
\hline $\begin{array}{l}\text { H.4 How frequently does your current job require } \\
\text { electronic mail? }\end{array}$ & Yes \\
\hline $\begin{array}{l}\text { H.14.How often is dealing with violent or physi- } \\
\text { cally aggressive people a part of your current } \\
\text { job? }\end{array}$ & No \\
\hline
\end{tabular}

Although we took inspiration from this indicator, we made a number of different choices. Dingel and Neiman (2020) selected 17 variables from O*NET's section $\mathrm{G}$ and section $\mathrm{H}$ to build their indicator, whereas we use 30 variables taken from the ICP's section $\mathrm{G}$ and section $\mathrm{H}^{21}$ All questions are listed in Table 12 . As shown, our indicator contains all the variables selected by Dingel and Neiman (2020) except a question regarding the relation with violent and physically aggressive people, since we deemed it quite ambiguous and unable to clearly detect profiles of non teleworkability. The integration of 14 additional variables goes into the direction of offering a more detailed picture of both the work context and the generalised activities that make it difficult teleworkability. Indeed, we enriched all the subgroups that constitute our indicator with one or more questions: doing outdoor activities $(+1)$, using specific equipment $(+5)$, being exposed to bio-chemical risk $(+3)$, performing highly physical and manual activities $(+4)$,

\footnotetext{
${ }^{21}$ Questions are taken from two sections of the ICP database on the work context (Section $\mathrm{H}$ ) and the generalised activities (Section G). More precisely, while Section H provides information on specific occupational requirements related to the context in which the work takes place, Section G lists occupation specific information on the type of generalized activities that have to be performed.
} 
Table 13 Comparison among Barbieri et al. (2021), Montenovo et al. (2020) and Cetrulo et al. (2020)

\begin{tabular}{|c|c|c|}
\hline Barbieri et al. (2021) & Cetrulo et al. (2020) & Dingel and Neiman (2020) \\
\hline H.21 Physical proximity (it enters reversely) & No & No \\
\hline $\begin{array}{l}\text { G.16 Performing general physical activities (it enters } \\
\text { reversely) }\end{array}$ & Yes & Yes \\
\hline G.19 Working with computers & No & No \\
\hline $\begin{array}{l}\text { G.20 Manoeuvring vehicles, mechanical vehicles or } \\
\text { equipment (it enters reversely) }\end{array}$ & Yes & Yes \\
\hline H.1 Face to face discussions (it enters reversely) & No & No \\
\hline H.8 Deal with external customers (it enters reversely) & No & No \\
\hline H.39 Time spend standing (it enters reversely) & No & No \\
\hline Montenovo et al. (2020) & Cetrulo et al. (2020) & Dingel and Neiman (2020) \\
\hline $\begin{array}{l}\text { H.3 How often do you have telephone conversations } \\
\text { in this job? }\end{array}$ & No & No \\
\hline H.4 How often do you use electronic mail in this job? & Yes & Yes \\
\hline $\begin{array}{l}\text { H.5 How often does the job require written letters and } \\
\text { memos? }\end{array}$ & No & No \\
\hline Montenovo et al. (2020) & Cetrulo et al. (2020) & Dingel and Neiman (2020) \\
\hline $\begin{array}{l}\text { H.3 How often do you have telephone conversations in } \\
\text { this job? }\end{array}$ & No & No \\
\hline H.4 How often do you use electronic mail in this job? & Yes & Yes \\
\hline $\begin{array}{l}\text { H.5 How often does the job require written letters and } \\
\text { memos? }\end{array}$ & No & No \\
\hline
\end{tabular}

having social contact $(+1)$. Increasing the number of variables enriches the information contained in the indicator and its underlying robustness to very specific questions, therefore it strengthens its ability in distinguishing jobs according to their teleworkability with more comprehensive and detailed criteria. Nonetheless, the two indicators still offer very similar results both in terms of occupational classification and econometric results. The percentage of jobs comparing the two indicators are presented in Table 14.

Barbieri et al. (2021) studies the Italian case and looks at three different attributes that characterise occupations, namely physical proximity, diseases exposure and possibility of working from home. Their "working from home" index is a composite indicator obtained from taking the average of seven questions from the ICP survey. Table 13 shows the variables used by Barbieri et al. (2021) that are slightly different from the one used both in our paper and in Dingel and Neiman (2020). However, many of them are quite similar, for instance use of e-mail correlates with working with computers; face to face discussion correlates with social interaction, and so on.

Bonacini et al. (2021) follows the methodology proposed by Barbieri et al. (2021), but proposes a dichotomous version of the indicator, first selecting the same seven questions chosen by Barbieri et al. (2021) from the ICP, then computing for 
each 5-digit occupation a composite index given by the average of the seven items' score and assigning to each job a binary dummy that takes value 1 (corresponding to "High FH Feasibility") if the composite index is higher than the sample mean, 0 (corresponding to "Low FH Feasibility") if otherwise. Therefore, starting from a continuous indicator, they recover a binary indicator (in terms of feasibility levels) to get more interpretable results.

Montenovo et al. (2020) builds two indicators: face to face and remote working. The latter is defined only by 3 questions on the use of e-mail, telephone, letters and memos. The value of each indicator is given by the average value of the $\mathrm{O} * \mathrm{NET}$ questions. In this case, the indicator is continuous.

Despite clear differences in the construction, mainly related to a discrete vs a continuous version and on the number of underlying selected questions, all indicators share a similar reasoning. Indeed, comparing the three binary indicators in Table 14, our indicator differs from Dingel and Neiman (2020) for a lower 6\% amount of NFH population, while the indicator by Bonacini et al. (2021) comprises a larger working from home group ( $+16 \%$ with respect to ours). Recall however that in the latter case the distinction is not on absolute teleworkability but rather on different degrees of teleworkability, based on the relative possibility of each job with respect to the average.

Table 14 Occupations and Indicators

\begin{tabular}{lll}
\hline & $\begin{array}{l}\text { Not from Home (\% } \\
\text { 4-digit jobs) }\end{array}$ & $\begin{array}{l}\text { From Home } \\
(\% \text { 4-digit } \\
\text { jobs })\end{array}$ \\
\hline Cetrulo et al. (2020) & 67 & 33 \\
Dingel and Neiman (2020) & 61 & 39 \\
Bonacini et al. (2021) & 51 & 49 \\
\hline
\end{tabular}

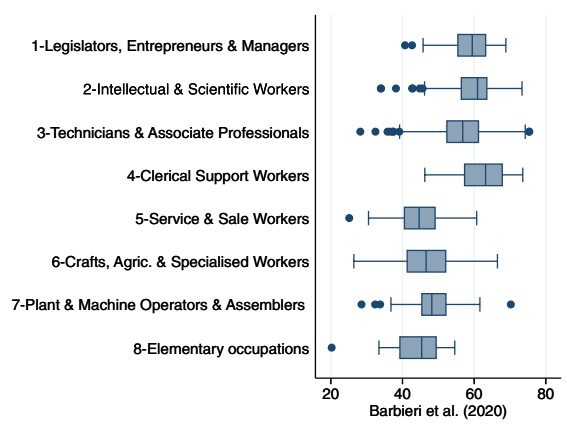

(a) Barbieri et al. (2021) indicator

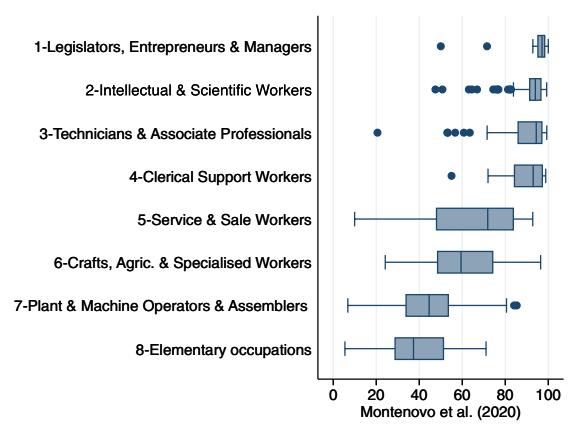

(b) Montenovo et al. (2020) Indicator

Fig. 14 Barbieri et al. (2021)'s and Montenovo et al. (2020)'s indicators of remote working across ISCO groups 
Table 15 Pairwise correlation across indicators

\begin{tabular}{|c|c|c|c|c|c|}
\hline & NFH & Dingel and Neiman & Barbieri et al & Bonacini et al & Montenovo \\
\hline NFH (discrete) & 1 & & & & \\
\hline $\begin{array}{l}\text { Dingel and Neiman (2020) } \\
\quad \text { (discrete) }\end{array}$ & $0.8680 *$ & 1 & & & \\
\hline $\begin{array}{l}\text { Barbieri et al. (2021) } \\
\text { (continuous) }\end{array}$ & $-0.6640 *$ & $-0.6685^{*}$ & 1 & & \\
\hline $\begin{array}{l}\text { Bonacini et al. (2021) } \\
\text { (discrete) }\end{array}$ & $-0.6014 *$ & $-0.6119^{*}$ & $0.8209^{*}$ & 1 & \\
\hline $\begin{array}{l}\text { Montenovo et al. (2020) } \\
\text { (continuous) }\end{array}$ & $-0.6040^{*}$ & $-0.6009^{*}$ & $0.5716^{*}$ & $0.5872 *$ & 1 \\
\hline
\end{tabular}

Turning to continuous indicators proposed by Barbieri et al. (2021) and Montenovo et al. (2020), Fig. 14 shows that they both capture remarkable differences between the upper and lower echelon of the ISCO classification scheme. Moreover, the pairwise correlation across both continuous and binary indicators shown in Table 15 is always higher than 0.6, suggesting a conceptual and empirical similarity across the indices. Only the Montenovo et al. (2020)'s indicator shows a lower correlation intensity, probably because of the smaller number of variables used to build the indicator of remote work. Notice that correlations are negative since we look at non working from home occupations, while the remaining (apart from Dingel and Neiman) identify jobs that can be done from home.

\section{Alternative compositions of the NFH indicator}

Consistently with Dingel and Neiman (2020), we have identified a threshold to account for the relative importance of a given task/activity for each occupation. Dingel and Neiman (2020) refer to activities and tasks that are often performed by workers. Our corresponding threshold to this notion of time prevalence is given by any value of the selected ICP questions that is equal or higher than 60 (on a 0-100 scale). Conversely, we have chosen the threshold of 40 out of 100 only for the use of e-mail since in this case we selected those jobs in which e-mails are only rarely used: 60 is indeed the threshold used also in the O*NET rating scale to attribute prevalence of a given activity. However, to test robustness with respect to the threshold, we compute two different NFH indicators using (i) a stringent threshold of $80 / 100$ for the 29 questions and 50/100 for the e-mail question; (ii) a relaxed threshold of 50/100 for the 29 questions and 20/100 for the e-mail question. Indeed, different thresholds might also give a glimpse of potential changes in the intensity of the activity. In general, increasing the threshold implies reducing the number of NFH occupations becoming the requirement more stringent and specific, moving from 67 to $48 \%$. Conversely, reducing the threshold implies increasing the number of NFH occupations becoming the requirement less stringent and specific, moving from 67 to $78 \%$ (Table 16). 


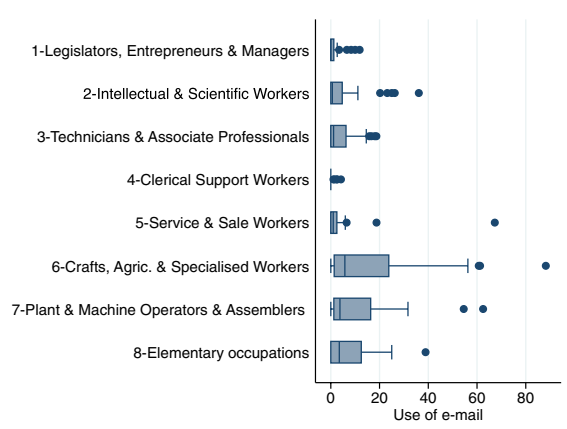

(a) Use of e-mail

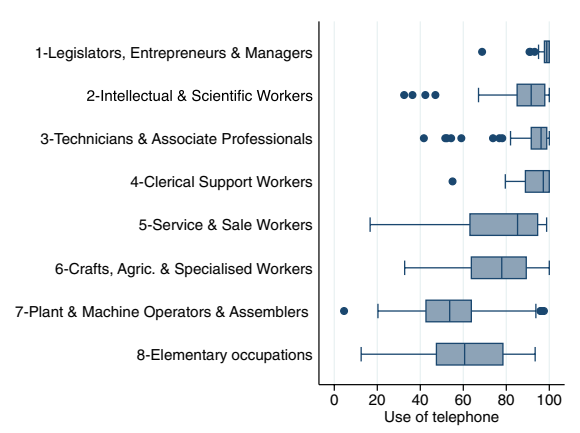

(b) Use of telephone

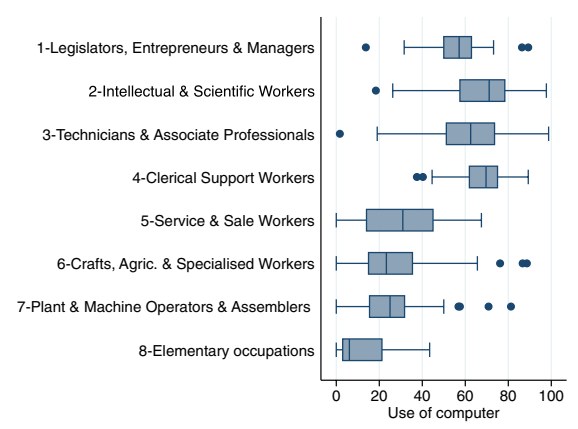

(c) Use of computer

Fig. 15 Use of e-mail, telephone and computer, box-and-whisker plots across ISCO groups

Table 16 Occupations and Indicator's alternatives

\begin{tabular}{lll}
\hline & $\begin{array}{l}\text { Not Working from Home }(\% \\
\text { jobs) }\end{array}$ & $\begin{array}{l}\text { Working From } \\
\text { Home (\% jobs) }\end{array}$ \\
\hline NFH (Cetrulo et al., 2020) & 67 & 33 \\
NFH (threshold 80/50) & 48 & 51 \\
NFH (threshold 50/20) & 78 & 22 \\
NFH with Pc (no mail) & 68 & 32 \\
NFH with Pc and telephone (no mail) & 68 & 32 \\
\hline
\end{tabular}

Furthermore, we also substitute the e-mail variable (question H.4) with alternative and similar questions that could predict as well higher possibilities of performing the job remotely, namely the use of computer and the use of telephone. Substituting the question on e-mail with a question on the use of computer does not change significantly the explanatory power of our indicator as the percentage of jobs in the two groups remains almost the same (Table 16). Adding both computer and telephone leaves the results unchanged. Therefore, given the similar degree of variability across occupations of these variables (Table 16), building a FH indicator that contains all of them risks to be redundant, as confirmed also by the correlation matrix in Table 17 (Figs. 14, 15). 
Table 17 Pairwise correlation across indicators with different thresholds and new variables

\begin{tabular}{llllll}
\hline & NFH & NFH 50 & NFH 80 & NFH with PC & $\begin{array}{l}\text { NFH with Pc } \\
\text { and Telephone }\end{array}$ \\
\hline NFH & 1.0000 & & & & \\
NFH 50/20 & $0.7487^{*}$ & 1.0000 & & & \\
NFH 80/50 & $0.6663^{*}$ & $0.5120^{*}$ & 1.0000 & & 1.0000 \\
NFH with Pc & $0.9551^{*}$ & $0.7522^{*}$ & $0.6626^{*}$ & 1.0000 & \\
$\begin{array}{l}\text { NFH with Pc and } \\
\text { Telephone }\end{array}$ & $0.9551^{*}$ & $0.7522^{*}$ & $0.6626^{*}$ & $1.0000^{*}$ & \\
\hline
\end{tabular}

\section{Econometric estimations with alternative indicators}

After having described differences and similarities among all the listed indicators, we proceed with the empirical estimation of our main models substituting the NFH indicator with the binary indicators of Dingel and Neiman (2020), Bonacini et al. (2021) and different combinations of thresholds and set of variables. Unfortunately, we could not apply the continuous indicators such as the one of Barbieri et al. (2021), since in this case it would have been difficult to provide a clear interpretation, but we proceeded with the estimation of Bonacini et al. (2021)'s indicator that is, as already explained, based on Barbieri et al. (2021)'s methodology.

All results of our baseline models hold, that is being a worker employed in a NFH occupation increases the risk of earning low income and losing job with respect to a worker employed in a FH occupation (Tables 18 and 19). Furthermore, using occupations data we also observe that NFH jobs experience higher risk of low income (Table 20) and health risk at work with respect to FH jobs (Table 21). Notice that in the case of Bonacini et al. (2021)'s indicator, the estimated coefficient is negative implying that moving from an occupation with a low telework feasibility to an occupation with a high telework feasibility reduces the risk of unemployment, low income and health risk. This is consistent with our empirical results.

\section{Factor analysis on NFH variables}

In order to study the information contained in our NFH indicator, we have performed a factor analysis to detect those different attributes that can influence the teleworkability of a given occupation. In particular, we investigate how the selected variables distribute and cluster according to their variability across 4-digit occupations. Interestingly, this empirical exercise allows us to pinpoint categories of workers according to the emerging factors that collect different sets of tasks and work contexts (Table 22). Factors are presented in descending order with respect to the degree of variance explained (as shown by Table 23).

The first factor is defined by those activities more directly related to blue-collar jobs, such as keeping sequence of machinery, managing processes and repairing equipment, therefore labelled "Manufacturing"; the second factor focuses on 


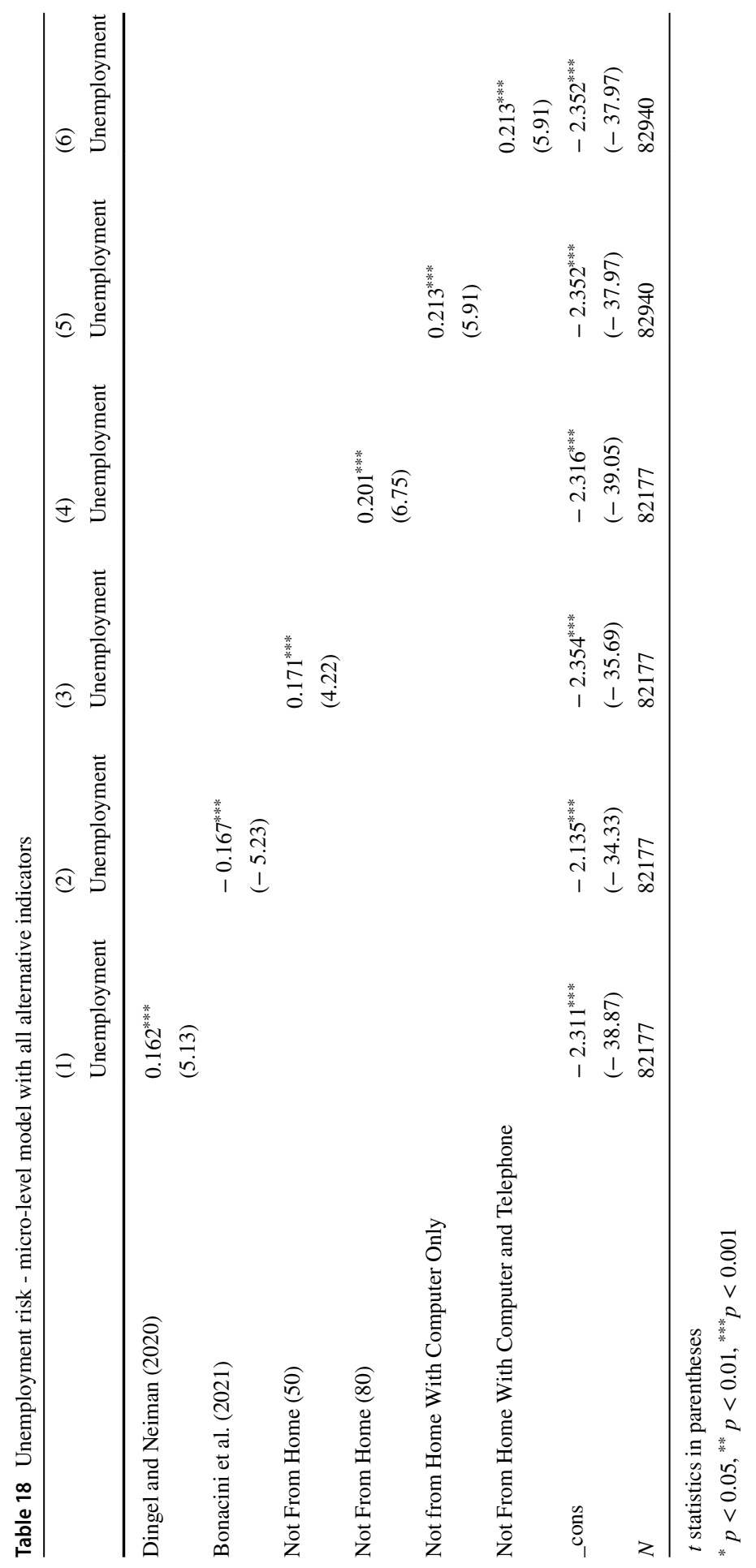




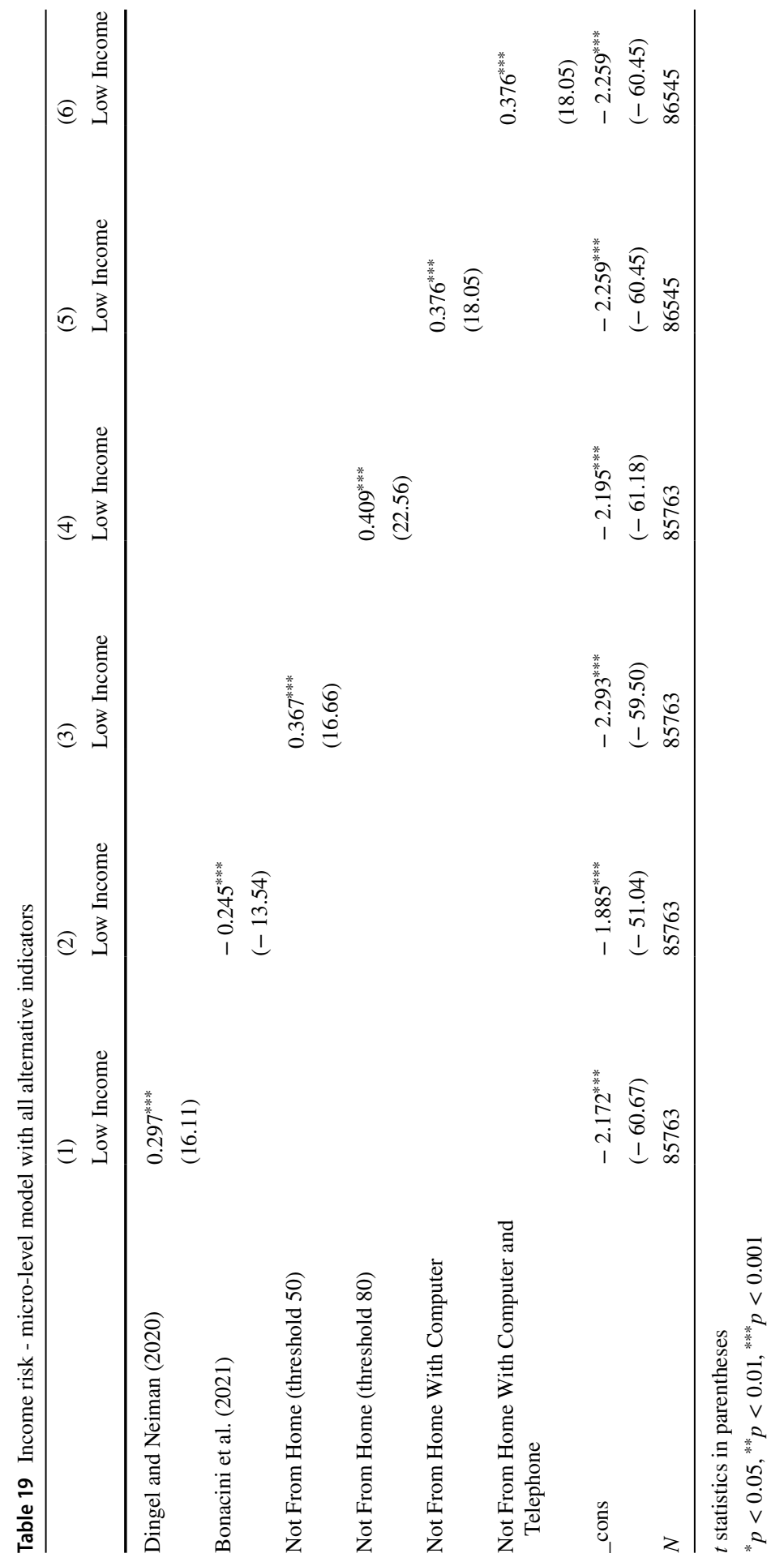




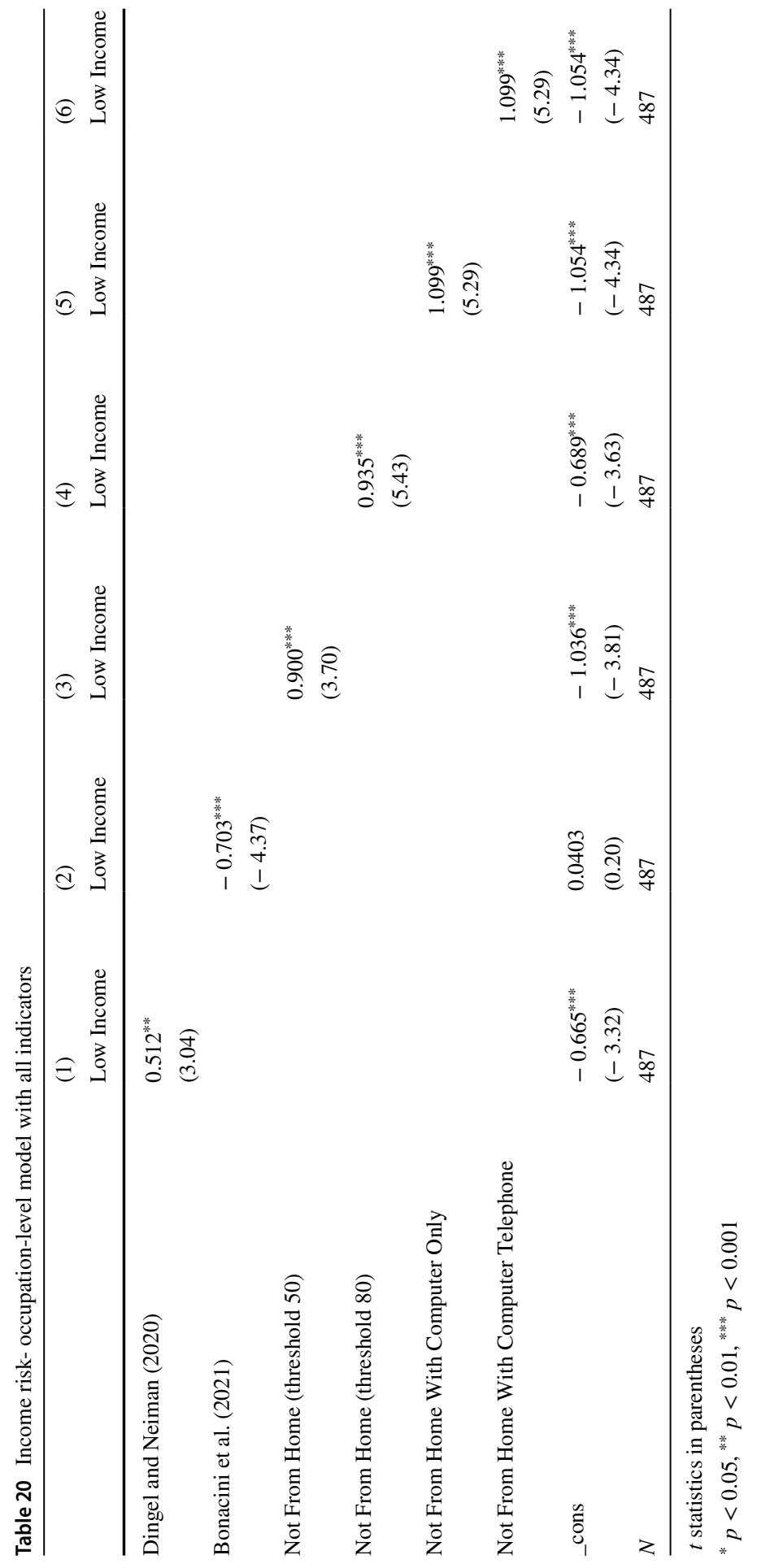


Table 21 Health risk - occupation-level model with all indicators

$\begin{array}{llllll}\text { (1) (2) (3) } & \text { (4) }\end{array}$

Health Risk Health Risk Health Risk Health Risk Health Risk Health Risk

Dingel and Neiman

(2020)

$1.206^{* * *}$

$(5.81)$

Bonacini et al. (2021)

$$
\begin{aligned}
& -0.833^{* * *} \\
& (-5.00)
\end{aligned}
$$

Not From Home

(threshold 50)

Not From Home

(threshold 80)

Not From Home With

Computer

Not From Home

With Computer and

Telephone

\begin{tabular}{lllllll} 
_cons & $-2.140^{* * *}$ & $-0.879^{* * *}$ & $-2.318^{* * *}$ & $-1.827^{* * *}$ & $-2.316^{* * *}$ & $-2.316^{* * *}$ \\
& $(-7.69)$ & $(-3.84)$ & $(-7.27)$ & $(-7.62)$ & $(-6.47)$ & $(-6.47)$ \\
$N$ & 485 & 485 & 485 & 485 & 485 & 485 \\
\hline
\end{tabular}

$t$ statistics in parentheses

${ }^{*} p<0.05,{ }^{* *} p<0.01,{ }^{* * *} p<0.001$

physical tasks, such as moving, handling objects, labelled "Logistics and Distribution". The third factor is described by outdoor activities, use of vehicles like tractors and relates to "Agriculture" jobs; whereas the fourth factor refers to facing dangerous situations, climbing ladders and wearing protective equipment, therefore referring to the "Construction" sector. The last factor describes explicitly the "Health and care" sectors, since the variables that load more on it are taking care of other people, being exposed to infection and radiation.

This further empirical exercise is quite useful in confirming the validity of our indicator, since the factor analysis reveals that the variables chosen to build the index are able to identify and describe different types of jobs that, for diverse characteristics, cannot be performed from home, therefore they were neither redundant nor trivially included. The five factors explains $70 \%$ of the data-set variability (cumulative variance in Table 23). 


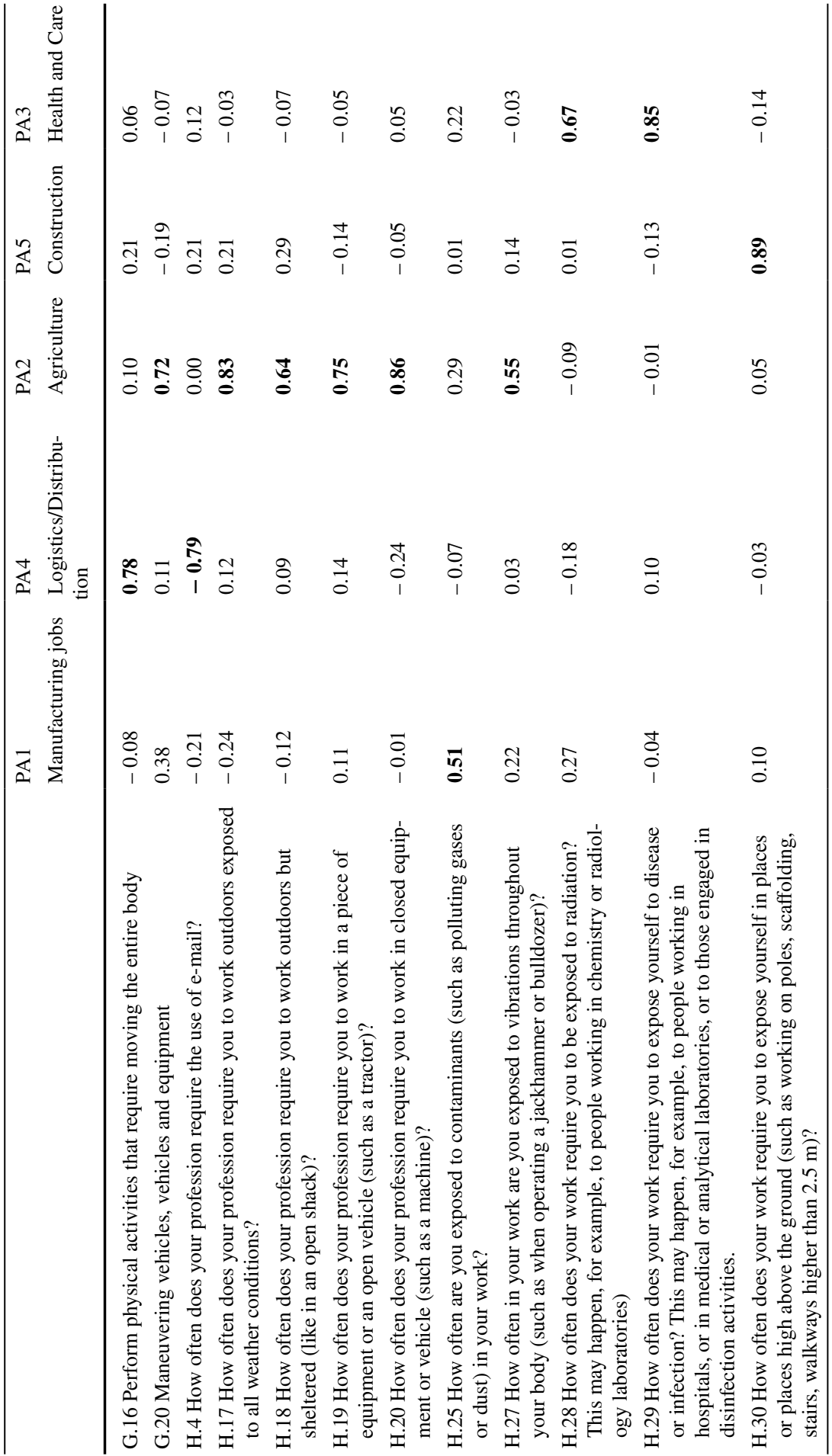




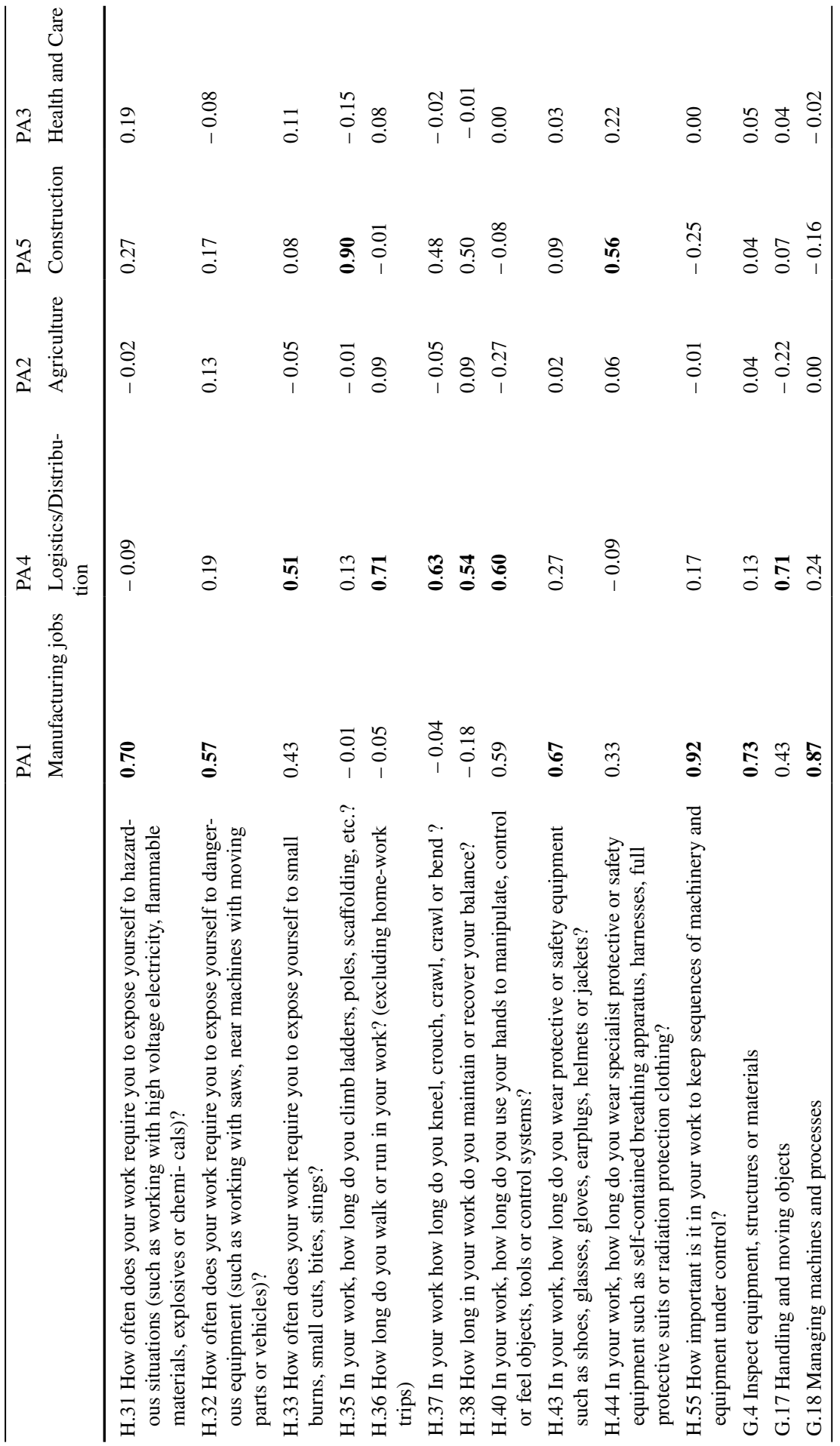




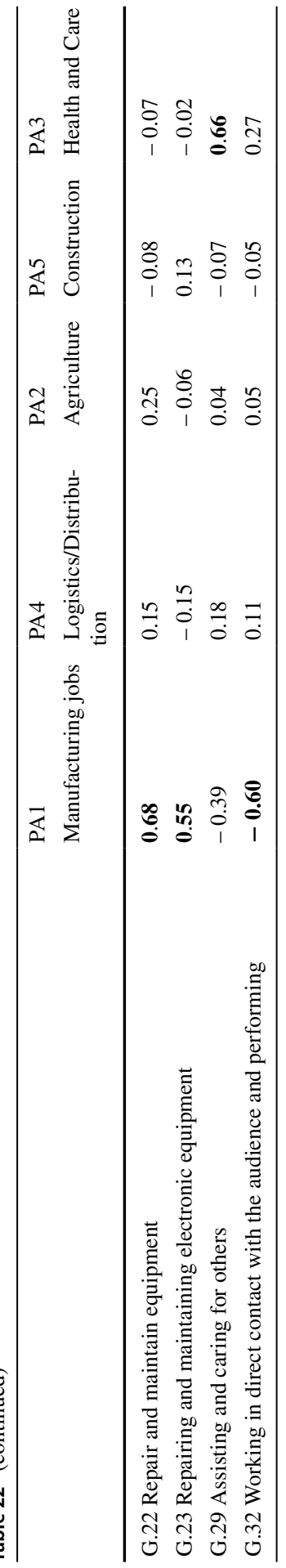


Table 23 Variance explained by the factor model

\begin{tabular}{llllll}
\hline & $\begin{array}{l}\text { PA1 } \\
\text { Manufacturing }\end{array}$ & $\begin{array}{l}\text { PA4 } \\
\text { Logistic/ } \\
\text { Distribu- } \\
\text { tion }\end{array}$ & $\begin{array}{l}\text { PA2 } \\
\text { Agriculture }\end{array}$ & $\begin{array}{l}\text { PA5 } \\
\text { Construction }\end{array}$ & $\begin{array}{l}\text { PA3 } \\
\text { Health and Care }\end{array}$ \\
\hline SS loadings & 7.01 & 5.02 & 3.81 & 3.36 & 1.88 \\
Proportion variance & 0.23 & 0.17 & 0.13 & 0.11 & 0.06 \\
Cumulative variance & 0.23 & 0.40 & 0.53 & 0.64 & 0.70 \\
Proportion explained & 0.33 & 0.24 & 0.18 & 0.16 & 0.09 \\
Cumulative proportion & 0.33 & 0.57 & 0.75 & 0.91 & 1.00 \\
\hline
\end{tabular}

\section{References}

Adams-Prassl, A., Boneva, T., Golin, M., \& Rauh, C. (2020). Furloughing. Fiscal Studies, 41(3), 591-622.

Adams-Prassl, A., Boneva, T., Golin, M., \& Rauh, C. (2020). Inequality in the impact of the coronavirus shock: Evidence from real time surveys. Journal of Public Economics, 189, 104245.

Alipour, J.-V., Falck, O., Schüller, S. (2020). Germany's capacities to work from home. CESifo Working Paper, No. 8227.

Arntz, M., Sarra, B. Y., \& Berlingieri, F. (2019). Working from home: Heterogeneous effects on hours worked and wages. ZEW-Centre for European Economic Research Discussion Paper (19-015).

Bailey, D. E., \& Kurland, N. B. (2002). A review of telework research: Findings, new directions, and lessons for the study of modern work. Journal of Organizational Behavior: The International Journal of Industrial, Occupational and Organizational Psychology and Behavior, 23(4), 383-400.

Bailey, N., \& Kurland, N. B. (1999). The advantages and challenges of working here, there, anywhere, and anytime. Organizational Dynamics, 28(2), 53-68.

Barbieri, T., Basso, G., \& Scicchitano, S. (2021). Italian workers at risk during the covid-19 epidemic. Italian Economic Journal, 1-21.

Beland, L.-P., Brodeur, A., Wright, T. (2020). Covid-19, stay-at-home orders and employment: Evidence from cps data. IZA Discussion Papers, No. 13282.

Bloom, N., Liang, J., Roberts, J., \& Ying, Z. J. (2015). Does working from home work? Evidence from a Chinese experiment. The Quarterly Journal of Economics, 130(1), 165-218.

Boeri, T., Caiumi, A., \& Paccagnella, M. (2020). Mitigating the work-safety trade-off. CEPR Covid Economics, 2, 60-66.

Bonacini, L., Gallo, G., \& Scicchitano, S. (2021). Working from home and income inequality: Risks of a 'new normal' with covid-19. Journal of Population Economics, 34(1), 303-360.

Brussevich, M., Dabla-Norris, E., \& Khalid, S. (2020). Who will bear the brunt of lockdown policies? evidence from tele-workability measures across countries. IMF Working Paper.

Brynjolfsson, E., Horton, J. J., Ozimek, A., Rock, D., Sharma, G., \& TuYe, H.-Y. (2020). Covid-19 and remote work: An early look at us data. NBER Working Paper, No. 27344.

Cassandro, N., Centra, M., Esposito, P., \& Guarascio, D. (2021). What drives employment-unemployment transitions? evidence from italian task-based data. Economia Politica, 38(3), 1109-1147.

Cetrulo, A., Guarascio, D., \& Virgillito, M. E. (2020). Anatomy of the Italian occupational structure: Concentrated power and distributed knowledge. Industrial and Corporate Change, 29(6), 1345-1379.

Cetrulo, A., Guarascio, D., \& Virgillito, M. E. (2020). The privilege of working from home at the time of social distancing. Intereconomics, 55, 142-147.

Cetrulo, A., Sbardella, A., \& Virgillito, M. E. (2021). "Vanishing social classes? Facts and figures of the Italian labour market”. Lem WP Series, 29/2021.

Cirillo, V., Evangelista, R., Guarascio, D., \& Sostero, M. (2021). Digitalization, routineness and employment: An exploration on Italian task-based data. Research Policy, 50, 104079. 
Cirillo, V., Fana, M., \& Guarascio, D. (2017). Labour market reforms in Italy: evaluating the effects of the jobs act. Economia Politica, 34(2), 211-232.

Corso, M., Martini, A., Pellegrini, L., Massa, S., \& Testa, S. (2006). Managing dispersed workers: The new challenge in knowledge management. Technovation, 26(5-6), 583-594.

Del Boca, D., Oggero, N., Profeta, P., \& Rossi, M. (2020). Women's and men's work, housework and childcare, before and during covid-19. Review of Economics of the Household, 18(4), 1001-1017.

Delaporte, I., Escobar, J., \& Peña, W. (2021). The distributional consequences of social distancing on poverty and labour income inequality in latin america and the caribbean. Journal of Population Economics, 34, 1385-1443.

Dingel, J. I., \& Neiman, B. (2020). How many jobs can be done at home? Journal of Public Economics, 189, 104235.

Dosi, G., Fanti, L., Virgillito, M. E., et al. (2020). Unequal societies in usual times, unjust societies in pandemic ones. Journal of Industrial and Business Economics, 47, 371-389.

Dueñas, M., M. Campi, \& L. Olmos (2020). Changes in mobility and socioeconomic conditions in bogot \'a city during the covid-19 outbreak. arXiv:2008.11850.

Dutcher, E. G. (2012). The effects of telecommuting on productivity: An experimental examination. the role of dull and creative tasks. Journal of Economic Behavior \& Organization 84(1), 355-363.

EFFAT (2020). Covid-19 outbreaks in slaughterhouses and meat processing plants. Technical report. https://effat.org/wp-content/uploads/2020/09/Covid-19-outbreaks-in-slaughterhouses-and-meatprocessing-plants-State-of-affairs-and-demands-for-action-at-EU-level-7.09.2020.pdf.

ETUI (2020). Covid-19 point épidémiologique hebdomadaire du 10 septembre 2020. Technical report. https://www.etui.org/sites/default/files/2020-09/COVID19_PE_20200910.pdf.

Farré, L., Fawaz, Y., González, L., Graves, J (2020). How the covid-19 lockdown affected gender inequality in paid and unpaid work in Spain. IZA Discussion Papers, No. 13434

Fondazione Di Vittorio (2020). Quando lavorare da casa è smart? Prima indagine Cgil/Fondazione Di Vittorio sullo smart working. Technical report. http://www.cgil.it/admin_nv47t8g34/wp-content/ uploads/2020/05/Indagine_Cgil-Fdv_Smart_working.pdf.

Freeman, R. B., Ganguli, I., \& Handel, M. J. (2020). Within-occupation changes dominate changes in what workers do: A shift-share decomposition, 2005-2015. In AEA Papers and Proceedings, 110, 394-99.

Gonzalez, D., Karpman, M., Kenney, G. M., \& Zuckerman, S. (2020). Hispanic adults in families with noncitizens disproportionately feel the economic fallout from covid-19. Washington, DC: Urban Institute.

Gottlieb, C., Grobovšek, J., Poschke, M., \& Saltiel, F. (2021). Working from home in developing countries. European Economic Review, 133, 103679.

Guarascio, D. (2021). Gli ammortizzatori sociali durante la pandemia. la fase emergenziale e le riforme necessarie. Social Policies 8(1), 183-187.

Guven, C., Sotirakopoulos, P., \& Ulker, A. (2020). Short-term labour market effects of covid-19 and the associated national lockdown in australia: Evidence from longitudinal labour force survey. GLO Discussion Paper, No. 635.

Harkness, R. C. (1977). Technology assessment of telecommunications/transportation interactions. Volume II Detailed impact analyses, Stanford Research Institute.

Hensvik, L., Le Barbanchon, T., Rathelot, R. (2020). Which jobs are done from home? evidence from the american time use survey. CEPR Discussion Paper, No. DP14611.

Horton, R. (2020). Offline: Covid-19 is not a pandemic. The Lancet, 396(10255), 874.

Huws, U. (1991). Telework: projections. Futures, 23(1), 19-31.

Huws, U., N. Jagger, and S. O'Regan (1999). Teleworking and globalisation. Institute for Emploment Studies.

ILO (2020). A safe and healthy return to work during the covid-19 pandemic. Technical report. http:// www.ilo.org/wcmsp5/groups/public/---ed_protect/---protrav/---safework/documents/briefingnote/ wcms_745549.pdf.

INAIL (2020a). Documento tecnico sulla possibile rimodulazione delle misure di contenimento del contagio da sars-cov-2 nei luoghi di lavoro e strategie di prevenzione. Technical report. https://www. inail.it/cs/internet/docs/alg-documento-tecnico-coronavirus-fase-2.pdf.

INAIL (2020b). I dati sulle denunce da covid-19 (monitoraggio al 30 giugno 2020). Technical report. https://www.inail.it/cs/internet/docs/alg-scheda-tecnica-contagi-covid-30-giugno-2020.pdf.

ISTAT (2020). Nota metodologica: Occupati e disoccupati dati provvisori luglio 2020. Technical report. https://www.istat.it/it/files//2020/09/CS_Occupati-e-disoccupati_LUGLIO_2020.pdf. 
Lott, Y., \& Chung, H. (2016). Gender discrepancies in the outcomes of schedule control on overtime hours and income in Germany. European Sociological Review, 32(6), 752-765.

Makimoto, T., \& Manners, D. (1997). Digital Nomad. Amsterdam: Wiley.

Mas, A., \& Pallais, A. (2017). Valuing alternative work arrangements. American Economic Review, 107(12), 3722-59.

Messenger, J. C. (2017). Working anytime, anywhere: The evolution of telework and its effects on the world of work. IUSLabor.

Messenger, J. C. (2019). Telework in the 21st Century: An Evolutionary Perspective. Edward Elgar Publishing.

Milasi, S., González-Vázquez, I., Fernández-Mací as E. (2020). Telework in the eu before and after the covid-19: Where we were, where we head to. Science for Policy Brief.

Millett, G. A., Jones, A. T., Benkeser, D., Baral, S., Mercer, L., Beyrer, C., et al. (2020). Assessing differential impacts of covid-19 on black communities. Annals of Epidemiology, 47, 37-44.

Mongey, S. and A. Weinberg (2020). Characteristics of workers in low work-from-home and high personal-proximity occupations. Becker Friedman Institute for Economic White Paper.

Montenovo, L., Jiang, X., Rojas, F. L., Schmutte, I. M., Simon, K. I., Weinberg, B. A., \& Wing, C. (2020). Determinants of disparities in covid-19 job losses. National Bureau of Economic Research, No. w27132.

Neirotti, P., E. Paolucci, and E. Raguseo (2011). Diffusion of telework: Myth or reality? some stylized facts on telework diffusion in italian firms. In 2011 10th International Conference on Mobile Business, pp. 320-330. IEEE.

Nilles, J. (1975). Telecommunications and organizational decentralization. IEEE Transactions on Communications, 23(10), 1142-1147.

OECD. (2020). Productivity gains from teleworking in the post covid-19 era: how can public policies make it happen?. France: OECD Publishing Paris.

Olson, M. H. (1983). Remote office work: Changing work patterns in space and time. Communications of the ACM, 26(3), 182-187.

Palomino, J. C., Rodríguez, J. G., \& Sebastian, R. (2020). Wage inequality and poverty effects of lockdown and social distancing in Europe. European Economic Review, 129, 103564.

Saltiel, F. (2020). Who can work from home in developing countries. Covid Economics, 7(2020), 104-118.

Selden, T. M., \& Berdahl, T. A. (2020). Covid-19 and racial/ethnic disparities in health risk, employment, and household composition: Study examines potential explanations for racial-ethnic disparities in covid-19 hospitalizations and mortality. Health Affairs, 39(9), 1624-1632.

Singer, M., Bulled, N., Ostrach, B., \& Mendenhall, E. (2017). Syndemics and the biosocial conception of health. The Lancet, 389(10072), 941-950.

Sostero, M., S. Milasi, J. Hurley, E. Fernandez-Macías, and M. Bisello (2020). Teleworkability and the covid-19 crisis: a new digital divide? JRC working papers series on labour, education and technology, No. 2020/05.

Toffler, A. \& Alvin T.(1980). The third wave, Volume 484. Bantam books New York.

Vargas-Llave, O., Mandl, I., Weber, T., \& Wilkens, M. (2020). Telework and ict-based mobile work: Flexible working in the digital age. New Forms of Employment Series.

Vazquez, E., \& Winkler, H. (2017). How is the internet changing labor market arrangements? The World Bank: Evidence from telecommunications reforms in Europe. World Bank Policy Research Working Paper, n.7976.

Wooldridge, J. M. (2006). Introduction to econometrics: A modern approach. USA: Michigan State University.

Wright, E. O. (1980). Class and occupation. Theory and Society, 9(1), 177-214.

Wright, E. O. (1997). Class counts: Comparative studies in class analysis. Cambridge University Press.

Zamarro, G., \& Prados, M. J. (2021). Gender differences in couples' division of childcare, work and mental health during covid-19. Review of Economics of the Household, 19(1), 11-40.

Publisher's Note Springer Nature remains neutral with regard to jurisdictional claims in published maps and institutional affiliations. 